RUNNING HEAD: Social Identity Mapping Online

\title{
Social Identity Mapping Online
}

Sarah V. Bentley ${ }^{1}$, Katharine H. Greenaway ${ }^{2}$, S. Alexander Haslam ${ }^{1}$, Tegan Cruwys ${ }^{3}$, Niklas K. Steffens ${ }^{1}$, Catherine Haslam $^{1}$, \& Ben Cull ${ }^{4}$

\author{
${ }^{1}$ The University of Queensland, School of Psychology \\ ${ }^{2}$ Melbourne School of Psychological Sciences, University of Melbourne \\ ${ }^{3}$ Research School of Psychology, The Australian National University \\ ${ }^{4}$ bencull.com
}

\section{Author Note}

Work on this paper was supported by three Australian Research Council grants (DE160100761 awarded to the second author, FL110100199 awarded to the third author, and DP160102514 awarded to the third through sixth authors). The authors would like to thank Ashleigh Kelly, Magen Seymour-Smith, Heather O’Mahen, and Ben C. P. Lam for assistance with data collection and study preparation.

Address correspondence to Sarah Bentley, School of Psychology, The University of Queensland, Brisbane, QLD 4072, Australia. e-mail: s.bentley@uq.edu.au; tel.: +61 (0)7 33656230 
Masked Manuscript without Author Information
RUNNING HEAD: SOCIAL IDENTITY MAPPING ONLINE

Social Identity Mapping Online 


\begin{abstract}
Social identities play an important role in many aspects of life, not least in those pertaining to health and well-being. Decades of research shows that these relationships are driven by a range of social identity processes, including identification with groups, social support received from groups, and multiple group memberships. However, to date, researchers have not had access to methods that simultaneously capture these social identity processes. To fill this void, this paper introduces an online Social Identity Mapping (oSIM) tool designed to assess the multidimensional and connected nature of social identities. Four studies (total $N=$ 721) featuring community, student, new parent, and retiree samples, test the reliability and validity of oSIM. Results indicate that the tool is easy to use, engaging, has good internal consistency as well as convergent and discriminant validity, and predicts relevant outcomes across a range of contexts. Furthermore, using meta-analytic findings, the tool is able to index a higher-order social identity construct, here introduced as a supergroup. This new concept provides holistic information about groups (reflecting an integrated index of several social identity processes) that are predictive of well-being outcomes, as well as outcomes related to successful adjustment to challenging life events. We discuss how the tool can be used to tackle key debates in the literature and contribute to theory by affording researchers the opportunity to capture the nuanced and contextual nature of social identity in action.
\end{abstract}

Keywords: social identity mapping, social identity, group memberships, social cure 


\section{Social Identity Mapping Online}

Decades of research reveals that social connection is key to living a happy, healthy, and long life. Feeling connected to others is associated with better health, well-being, as well as social and cognitive functioning (Berkman \& Syme, 2017; Sani, 2012; for recent reviews see Haslam, Jetten, Cruwys, Dingle \& Haslam, 2018; Jetten et al., 2017). Maintaining these connections is particularly important when managing key transitional moments in life, such as transitioning to university, parenthood, forging a new professional identity, illness, or deciding to retire (Bentley, Peters, Haslam, \& Greenaway, 2019; Iyer, Jetten, Tsivrikos, Postmes, \& Haslam, 2009; Jetten, Haslam, Iyer, \& Haslam, 2009b; Lam et al., 2018; Seymour-Smith, Cruwys, Haslam, \& Brodribb, 2017; Walton, Logel, Peach, Spencer, \& Zanna, 2015). Investigating the role of social connections in these transitional moments, as well as their impact on health and well-being, is the goal of a burgeoning literature in the social identity space known colloquially as the social cure (e.g., Haslam, Jetten, Cruwys, Dingle, \& Haslam, 2018b; Jetten, Haslam, \& Haslam, 2012; Jetten et al., 2017).

The social cure literature has demonstrated the importance of group memberships and the social identities they afford — in determining health outcomes, including recovery from a stroke, depression, and addiction (Cruwys et al., 2013; Dingle, Stark, Cruwys, \& Best, 2015; Haslam et al., 2008). Increasingly in this literature, researchers are interrogating the psychological pathways that bridge social identities and personal well-being (Cruwys, Haslam, Dingle, Haslam, \& Jetten, 2014; Greenaway, Cruwys, Haslam, \& Jetten, 2016; Greenaway, Haslam, et al., 2015; Khan et al., 2014). Nevertheless, it remains the case that researchers' capacity to assess social identity and its processes is limited by the measurement tools at their disposal. The primary purpose of this paper is to introduce and test a new instrument — online Social Identity Mapping (oSIM) — which allows researchers to capture multiple key features of social identity at the same time. 


\section{Understanding Social Identity}

The social identity approach comprises two theories: social identity theory (Tajfel \& Turner, 1979) and self-categorization theory (Turner, Hogg, Oakes, Reicher, \& Wetherell, 1987b). Together, these theories outline the mechanisms through which social groups affect individual psychology. The key construct that is central to both theories is social identity, defined by (Tajfel, 1972, p.31) as "knowledge that [we] belong to certain social groups together with some emotional and value significance to [us] of this group membership." Selfcategorization theory presents a socio-cognitive account of social identity, and argues that identity changes as a function of environment: at work a woman may define herself in terms of her role as a lawyer or doctor, but when picking up her child from school may identify first and foremost as a mother. These contextual transformations reflect the fact that, in a range of social contexts, the substance of selfhood is shaped by groups to which people feel they belong and with which they identify (Ellemers, Spears, \& Doosje, 2002; Haslam \& Ellemers, 2011; Spears, Jetten, \& Scheepers, 2002).

Over the past four decades, research has identified a range of ways in which social identities structure individual psychology, including through their ability to provide meaning, support, and connection with others. For example, a large body of research shows that group memberships have psychological benefits through the provision and receipt of social support (Haslam, Reicher, \& Levine, 2012; Levine, Prosser, Evans, \& Reicher, 2005). Other work has shown that the degree to which a person feels representative or prototypical of a group is an important determinant of their ability to influence and lead others (Haslam, Reicher, \& Platow, 2011; Hogg, Van Knippenberg, \& Rast, 2012). Perhaps the most studied of social identity constructs - group identification — has been shown to improve individual cognition (Bentley, Greenaway, \& Haslam, 2017; Fratiglioni, Paillard-Borg, \& Winblad, 2004; Haslam, Morton, et al., 2012) and self-esteem (e.g., Jetten et al., 2015), as well as group 
communication (e.g., Greenaway, Wright, Willingham, Reynolds, \& Haslam, 2015) and productivity (Kane, 2010; Kane, Argote, \& Levine, 2005). Beyond support, representativeness, and positivity directed towards one particular group, other research has shown that the sheer number of groups one belongs to has psychological benefits. Indeed, this literature suggests that the more groups a person belongs to, the more likely they are to have access to resources such as support, that serve to structure health and well-being (Cruwys et al., 2013; Jetten et al., 2015).

Each of these lines of research speaks to the importance of the different social identity processes that are implicated in a person's ability to live a positive and rewarding life (i.e., identification, support, prototypicality, multiple group membership). To date, however, researchers' capacity to explore these processes have been limited by the fact that the main instruments at their disposal — whether multi-component inventories (Cameron, 2004; Ellemers, Kortekaas, \& Ouwerkerk, 1999; Jetten, Haslam, Pugliese, Tonks, \& Haslam, 2010; Leach et al., 2008) multi-item scales (Jetten et al., 2010; Kearns, Muldoon, Msetfi, \& Surgenor, 2018; van Breen, Spears, Kuppens, \& de Lemus, 2017), or single-item measures (Postmes, Haslam, \& Jans, 2013) — assess only one social identity process at a time (e.g., identification or prototypicality or multiple group membership). Importantly too, the fact that these instruments incorporate exclusively Likert-type self-report scales has some drawbacks for participants in that the task of responding to a (sometimes large) series of questions can become fatiguing, not to mention boring.

Existing assessment tools have, of course helped to develop a rich understanding of different social identity processes, but their limitations are evident in three distinct ways. First, they do not explore the full extent of a person's social group memberships and hence limit the scope of social identity-related data that can be analyzed. Second, they largely fail to capture the interconnected nature of such memberships, not least by neglecting inter- 
relationships between groups (e.g., their compatibility). Third, they can position the participant as a passive target in the research process subject to researchers' assumptions (e.g., about which group identifications are important to assess, and how these should be labelled; Liu, Wilson, McClure, \& Higgins, 1999). As we discuss later, an assessment process that positions participants more actively in creating and defining their social landscape may have benefits not only in terms of the extent and quality of data being captured, but also may have implications in the intervention space. The mapping tool we introduce in the present paper is designed to meet these challenges and open a new avenue of research into the dynamics of social identity.

\section{A Brief History of Identity Mapping}

The process of mapping out identities has been the focus of interest within psychological, sociological, and epidemiological research for decades. Some of this prior work focused on mapping the self-concept. For instance, Linville (1987) introduced a procedure for assessing self-complexity whereby participants sorted a range of trait cards into clusters of relevant traits they considered meaningful to their self-concept. Interestingly and in line with social identity assumptions - many of the trait clusters provided by Linville's participants appeared to map onto meaningful groups in one's life (e.g., family, friends, work colleagues, roommates), although this social level of analysis was not explicitly touched on in the original work. Follow-up research has found that the quantity of clusters (i.e., having more self-aspects) predicts resilience in the face of stress (Brown \& Rafaeli, 2007). Work on compartmentalization using the same self-concept sorting task suggests that it is the differentiation of clusters into positive and negative self-aspects that best predicts good mental health (Showers, 1992).

A related procedure can be found in work on self-concept mapping. In this procedure, participants begin with a blank sheet of paper on which they are encouraged to map their 
impression of the self. For example, Gresky and colleagues (2005) had participants begin with a central node labelled 'me' from which they could flesh out social connections and selfdefinitional qualities, ranging from personal qualities (e.g., hobbies) to group memberships (e.g., school, family, friends). This represents a hybrid approach that mixes the individuallyfocused self-complexity procedure with an appreciation that group memberships too represent an important component of the self. The self-concept mapping procedure has proved useful in mitigating psychological threat: Gresky and colleagues found that having participants draw self-concept maps with more compared to fewer nodes reduced the detrimental impact of stereotype threat on math performance (Gresky, Eyck, Lord, \& McIntyre, 2005). However, its utility as a potential indicator of the health or otherwise of people's social connections has not yet been fully explored in the literature.

Other research has considered identity mapping from a less individual and more socio-structural perspective (e.g., Hirsch, 1979). This research typically investigates the impact of social networks and social integration on health and well-being outcomes (Berkman \& Syme, 2017; Cohen, Doyle, Skoner, Rabin, \& Gwaltney, 1997; House, Landis, \& Umberson, 1988; Vogt, Mullooly, Ernst, Pope, \& Hollis, 1992). Barnes (1954) and Bott (1957) developed the concept of social networks to analyze the importance of social ties over and above more traditional groupings organized around kinship or geography. In this work, lack of social ties has been shown to reduce quality of life, and even to exacerbate a number of illnesses (Cohen et al., 1997; House et al., 1988).

Existing work on identity mapping to date has shown that the way people see themselves and others has a significant impact on health and well-being. However, each existing mapping process leaves some gaps unfilled. Self-complexity mapping provides insight into how people see themselves as individuals, but the social component of this process is not exploited. Social network mapping is undeniably social, but usually fails to 
incorporate participant perceptions of their social ties beyond who they spend time with (Paluck, Shepherd, \& Aronow, 2016). That is, while social network analysis provides a useful picture of 'who knows whom' in a particular community, it provides less information about how participants feel about those connections, including perceptions of positivity, supportiveness, and how those networks themselves relate. This is important because research suggests perceptions of one's social ties may be more predictive of well-being than the actual state of one's social ties (e.g., in the way that perceived social support is often more psychologically impactful than actual social support; Putnam, 2001; Putnam, Leonardi, \& Nanetti, 1993; Thoits, 1995). For example, Sani and colleagues (2012) found that the predictive value of actual social contact is modest in comparison to how one feels about the people with whom one has contact.

The process of social identity mapping has emerged as an alternative to existing tools. It aims to retain the autonomy and self-definitional components of self-complexity and selfconcept mapping, while also incorporating the explicitly social focus of network mapping. In doing so, it obtains information about people's relationships within their group memberships while retaining a structural perspective on relationships between those group memberships.

Social identity mapping. The concept of social identity mapping first emerged in embryonic form as part of the ASPIRe program developed for organizational contexts (Actualising Social Identity and Personal Identity Resources; Bentley, Greenaway, Haslam, \& Haslam, In preparation; Eggins, O' Brien, Reynolds, Haslam, \& Crocker, 2008; Haslam, Eggins, \& Reynolds, 2003; He et al., 2013; Reynolds, Eggins, \& Haslam, 2010). ASPIRe recruits workplace group memberships to explore determinants of workplace functioning and well-being and has proved beneficial for various research goals (e.g., by providing insights relevant to diversity management and leadership; see Haslam et al., 2017). However, researchers were not able to capitalize fully on the task's potential to capture important 
features of people's social identities in the workplace because there was no formalized process for harvesting the data it generated.

Social identity mapping was revived a few years later in a clinical context in which participants who were undergoing rehabilitation following stroke engaged in a facilitated mapping process as part of their neuropsychological assessment (Haslam et al., 2008; Jetten, Haslam, Iyer, \& Haslam, 2009a). This involved participants positioning Post-it notes on a sheet of A4 paper to create visual representations of their group memberships before and after their illness. This process allowed researchers and participants to create a map of social group memberships, and also provided a rich method for cataloguing the ways in which these changed over time (Jetten et al., 2009a). More recently, the same procedure was adapted as a way of tracking changes over time in the social group memberships of people recovering from substance abuse (Beckwith et al., 2018; Best et al., 2016).

Seeking to catalogue the utility of this process, Cruwys and colleagues (2016) conducted a series of studies that served to validate a paper-based format of social identity mapping (pSIM). In these studies, the mapping process was conducted in group sessions in which a facilitator guided participants through the process of creating their own social identity maps. Specifically, participants used separate Post-it notes to represent groups that were self-selected as relevant in their lives — choosing from small, medium, or large Post-it notes to represent groups of low, medium, and high importance, respectively. Participants then used Likert scales to rate the quality of their group memberships by answering questions about each group represented on each Post-it note, (e.g., 'How positive do you feel about this group?', 'How representative are you of this group?'). Finally, participants placed the Post-it notes on a sheet of paper in a spatial configuration that represented both the perceived similarity of groups to each other (with similar groups close together, and different groups far apart) and also their perceived compatibility (with straight lines drawn between two 
compatible groups and jagged lines drawn between two incompatible groups). The output of this pSIM process was a visual representation of a person's social group memberships that captured a considerable amount of information, including the number of groups in a person's life, as well as the perceived positivity, prototypicality, and compatibility of those groups.

The work of Cruwys and colleagues (2016) provides the platform for the creation and validation of the online mapping tool that we report here. This offline, paper-based mapping process was shown to be a reliable and valid way of assessing the multidimensional nature of social identity processes. Nevertheless, the pSIM relies on analogue methods of data entry that, as well as being time-consuming (and hence expensive), also have the capacity to introduce error into the data-gathering process. Moreover, the analogue version is restricted to face-to-face delivery contexts, and this makes it difficult to deliver the instrument to large numbers of participants simultaneously. It also introduces potential sources of variance associated with the delivery process (e.g., related to facilitator characteristics and style) which in turn restricts the potential use and comparability of social identity mapping in applied contexts. For these reasons, we sought to develop a tool that incorporated and refined all key features of existing versions of the pSIM, but that could be performed online. ${ }^{1}$ All that is required to complete oSIM is access to a device with a screen (e.g., computer, tablet, smart phone) that can be connected to the internet.

\section{Theoretical Contributions}

The oSIM tool provides improvements in methodological breadth, rigor, and engagement relative to traditional social identity measures. It also fills methods-based gaps

left by existing forms of identity mapping. In addition to these methodological benefits, oSIM

\footnotetext{
${ }^{1}$ We should note that we do not see oSIM as a full replacement for pSIM, believing that the mapping process may require face-to-face facilitation under certain circumstances. For instance, certain vulnerable participant populations (e.g., some clinical samples) or populations with limited access to or understanding of technology (e.g., some aged care samples) may benefit from an in person and tactile delivery method.
} 
opens new avenues for theoretical development within and beyond the social identity

literature. These theoretical contributions center in three main areas: the tool's ability to provide insight into identity benefits, identity change, and identity intervention.

First, oSIM has the capacity to explore in greater theoretical depth what exactly it is about social connections that is beneficial for relevant outcomes including health and wellbeing. For example, an implicit debate in the social identity literature has concerned the degree to which the number of group memberships (quantity) influences well-being compared to the quality of people's connections to those group memberships. Indeed, such a debate is not limited to the social identity literature, but features also in epidemiological work where researchers are divided over whether it is the number of connections or the depth of those connections that is better for health (Berkman, Glass, Brissette, \& Seeman, 2000; Berkman \& Syme, 2017; Cohen et al., 1997). Some research even argues that quantity is valued (and presumably beneficial) in early life stages, while quality is valued in later life stages (Carstensen, 2006).

It therefore remains an open question whether quantity or quality of group memberships (or some combination of the two) is most beneficial for health and well-being. Resolving this question is critical to establishing practical recommendations for improving well-being, and oSIM is extremely well-placed to do this. Because it provides a rich amount of data in one sitting (e.g., about quantity of groups, quality of groups, connections between groups) on scales that are directly comparable and collected at the same time, oSIM is capable of more precisely testing the quality vs. quantity question than other instruments. Moreover, its ease of delivery means oSIM is able to be completed by participants in a range of different life contexts and periods. This means data can be gathered from participants at multiple timepoints over the lifespan in order to test theories, such as those laid out in socioemotional selectivity theory (Carstensen, 2006). In the present research we aim to test 
directly whether quantity vs. quality of social connections predicts greater well-being in order to demonstrate the theoretical benefits of the tool in this regard. To this, we introduce a new concept to the literature that is capable of summarizing the qualities that are necessary for groups to improve well-being. Based on both theory and a meta-analysis of the results of our studies, we create an index for a supergroup - a group that has high quality and meaning for participants. In this, we reveal the components that contribute to groups predicting resilience over time.

Second, oSIM can be used to explore novel questions relating to identity change. Moments in life of identity transition are known to be disruptive of health and well-being. Yet, it is still relatively unknown what kinds of adjustments to social connectedness can be most protective in these times of struggle. In the social identity literature, the Social Identity Model of Identity Change (Haslam, Steffens, et al., 2019; Jetten \& Pachana, 2012) states that it is a combination of maintenance of existing groups alongside acquisition of new groups over the course of a major life transition that are important for health. The oSIM tool is uniquely well-placed to test this hypothesis, given that it collects information about a person's social landscape as they experience it. This means researchers can compare a person's social world before, during, and after important identity change phases to assess whether groups are maintained, lost, or added to, as well as whether existing relationships with those groups change over time. We do this in the present research across three contexts of major life transition: associated with new education contexts (Yeager, Walton, et al., 2016), new parenthood (Bugental et al., 2002) and changes in work status (Lam et al., 2018). Finally, oSIM can be used in programs designed to facilitate identity intervention. Many interventions in recent years have focused on increasing social connectedness and improving people's relationships with important groups (e.g., in education; Stephens, Hamedani, \& Destin, 2014; Walton \& Cohen, 2011; Walton et al., 2015). Particularly with 
general belongingness interventions, there is value in being able to visualize (changes in)

people's social connections, and thus directly and behaviorally assess the proposed

mechanism for psychological improvement. Indeed, social identity mapping has already been

used in one such intervention in the clinical context that was shown to reduce social isolation,

anxiety and depression (Haslam, Cruwys, et al., 2019; Haslam, Cruwys, Haslam, Dingle, \&

Chang, 2016). In this and other contexts, the tool can also be used as a discussion point with

participants to highlight their agency over changing their social landscape.

\section{The Present Research}

In the present research we develop and introduce online Social Identity Mapping, validate its psychometric properties and predictive value, and establish its theoretical utility. In search of oSIM's ability to provide insight into identity benefits, we focus on constructs that relate to the quantity and quality of social identities, and their relationship with outcomes related to health and well-being. We use oSIM to examine the degree to which mere number of groups is predictive of well-being in the absence of other indicators of the quality of connection with those groups. Some recent research suggests that the number of groups people belong to predicts well-being (Jetten et al., 2015), but such work has tended to conflate quantity with quality in measurement by asking about how many meaningful groups people belong to. Our intuition was that quantity of group memberships alone is unlikely to have a strong impact on well-being, drawing on Tajfel's original definition of social identities as requiring emotional significance, as well as modern refinements to the theory (Haslam, Jetten, et al., 2018b; Jetten et al., 2012; Sani, Madhok, Norbury, Dugard, \& Wakefield, 2015; Tajfel, 1972). In particular, we expected to find evidence for a key hypothesis specified within the social cure literature; namely, the multiple identities hypothesis, which specifically predicts that quality and quantity of group memberships operate in concert to scaffold health: 
Providing they are compatible with each other, important to them, and positive, the more social identities a person has access to, the more psychological resources they can draw upon and the more beneficial this will be for their health. (Haslam, Jetten, et al., 2018, p.26; Jetten et al., 2017, p.797)

This hypothesis states that belonging to more groups should be beneficial for well-being, but only to the degree that those groups are seen as psychologically valuable and positive. Using the oSIM tool, it is possible to test the multiple identities hypothesis more precisely than in previous research, because oSIM allows for simultaneous measurement of multiple relevant social identity constructs. In the present research, we chose a selection of such constructs based on our reading of the social cure literature and our desire to test the multiple identities hypothesis. Details of these constructs, and their theoretical relevance, are outlined below.

\section{Quantity of Group Memberships}

Number of groups. Empirical research shows that feeling connected to multiple groups is associated with good mental health. More specifically, belonging to multiple groups has been shown to predict (a) better health and well-being (Brook, Garcia, \& Fleming, 2008) (b) lower likelihood of depression relapse (Cruwys et al., 2013), (c) increased physical resilience (Jones \& Jetten, 2011), and (d) higher self-esteem (Jetten et al., 2015). Accordingly, one key finding of this work is that, when it comes to group memberships, 'the more the merrier' - so that, for example, belonging to multiple groups buffers people from the negative impact of life transitions (e.g., moving to university; Iyer, Jetten, Tsivrikos, Postmes, \& Haslam, 2009; having a stroke, Haslam et al., 2008). We operationalize this construct as the total number of groups people include in their online maps.

Number of high-contact groups. Related to the question of how many groups participants belong to, another relevant process is the amount of time a person spends interacting with those groups. Although research suggests that this predicts only a small 
amount of variance in well-being (Sani, 2012), contact can nevertheless serve as an important descriptive feature of a person's group memberships — such that they generally have more impact on a person (and hence their psychology and behavior) the more frequently they engage with those groups. Indeed, some research has shown that time spent with other people is a predictor of better health (Cohen, Doyle, Turner, Alper, \& Skoner, 2003). We therefore sought to explore this as another identity-relevant process. This is operationalized as the number of groups that a person had contact with at least once a week.

\section{Quality of Group Memberships}

Number of positive groups. Previous research has shown that it is groups one feels positive about which contribute positively to self-esteem (Tajfel \& Turner, 1979) and are especially important for well-being (Cruwys et al., 2014; Greenaway, Haslam, et al., 2015; Greenaway, Wright, et al., 2015). In part, this reflects the fact that a group's perceived positivity is one of the factors that determines whether or not people identify with it such that it is internalized as an important part of the self (Cruwys et al., 2014; Dutton, Roberts, \& Bednar, 2010; Jetten et al., 2015; Leach, Ellemers, \& Barreto, 2007; Turner, Hogg, Oakes, Reicher, \& Wetherell, 1987a). This claim is supported by a large body of work which shows that group memberships are more predictive of mental health and well-being the more they are subjectively experienced as positive and meaningful (e.g., Cruwys et al., 2014; Greenaway, Haslam, et al., 2015). To assess this, we asked participants to indicate how positive they felt about each group in their social identity map. We then operationalized this construct as the number of groups that were rated above the scale mid-point on positivity (Sani et al., 2015).

Number of representative groups. Previous research suggests that feeling prototypical of a group also has implications for a person's well-being (Ellemers \& Jetten, 2013). In large part this is because self-prototypicality is an index of the degree to which the 
self and the group are perceived to be interchangeable — so that the state of the group is perceived to have direct relevance for the self (Hogg \& Hardie, 1992; Waldzus, Mummendey, \& Wenzel, 2005). In order to index this, we asked participants to indicate how representative they felt of each group in their map. This construct was then operationalized as the number of groups that were rated above the scale mid-point for representativeness.

Number of supportive groups. Social support is widely recognized as a predictor of health (Holt-Lunstad, Smith, \& Layton, 2010; Schwarzer \& Leppin, 1991) but social identity research specifically suggests that its positive effects are contingent upon being supported by one's ingroups (rather than outgroups; Haslam, Reicher, et al., 2012). Accordingly, the number of ingroups from which one receives support is predicted to be a particularly important predictor of well-being. To capture this directly, we asked participants to indicate how much support they received from each of their groups. This was then operationalized as the number of groups that were rated above the scale mid-point for supportiveness.

Proportion of compatible groups. Finally, previous research has shown that the perceived similarity between groups (Yeager, Romero, et al., 2016), as well as compatibility of groups within a person's network of social group memberships, are both important determinants of well-being (Hirsh \& Kang, 2016; Iyer et al., 2009; Rosenthal, London, Levy, \& Lobel, 2011). This is because incompatibility can create various forms of identity (and behavioral) conflict that have a destabilizing impact on psychological and social functioning (e.g., in ways discussed by Hirsh \& Kang, 2016). Although we assess similarity in oSIM by having participants place similar groups close together and different groups farther apart, this functionality is difficult to compare across different devices (e.g., laptops vs. smartphones). We therefore focused on compatibility as our final dimension of group quality. This was captured by asking participants to draw lines between pairs of groups that indicated the degree to which these fit (or did not fit) well together. As a summative index, we then 
computed the proportion of links in each map that were rated as compatible. ${ }^{2}$

\section{The oSIM Procedure}

Here, we provide an overview of the tool from the perspective of a participant.

Complementary to the following description, we recommend watching the oSIM demonstration video, available http:/www.socialidentitynetwork.com/sim-info. Participants access the oSIM tool via a url link. The landing screen of oSIM comprises a large pop-up text box that welcomes participants and provides examples of different types of groups - family groups, sports groups, professional groups, and so on. This text can be adapted for the particular socio-demographic and/or cultural context of a given study.

Participants complete an interactive on-screen tutorial presenting instructions on how to build a social identity map. The map creation takes the following sequence: (1) identifying and naming the groups in one's life; (2) deciding on the importance of each group; (3) answering questions about each group (e.g., how positive one feels about the group); (4) positioning the groups so that similar groups are closer together; and (5) rating the (in)compatibility of pairs of groups in the map. The tutorial takes about two minutes to complete, and concludes by inviting participants to create their own social identity map. Participants are reminded that there is a Help button which explains the various components of the map creation process. An example of a completed identity map is provided in Figure 1 (see also Appendix 1 for an overview of the mapping procedure and Appendix 2 for the wording presented to participants). ${ }^{3}$ The oSIM tool is publicly available for researchers at a small cost-recovery fee. More information about oSIM and how to access it can be found at the following link: http://www.socialidentitynetwork.com/sim-info/.

\footnotetext{
${ }^{2}$ We thus assess positivity, representativeness, and support as raw counts and compatibility as a proportional count. The results with the first three quality dimensions as proportions and raw compatibility are reported in Supplementary Materials (tables S6 -S8).

${ }^{3}$ This procedure represents the final version of the tool. A pilot study $(N=80)$ informed the development of oSIM and thus used an earlier prototype that did not include help videos or exit checks. Full details are provided in Supplementary Materials.
} 


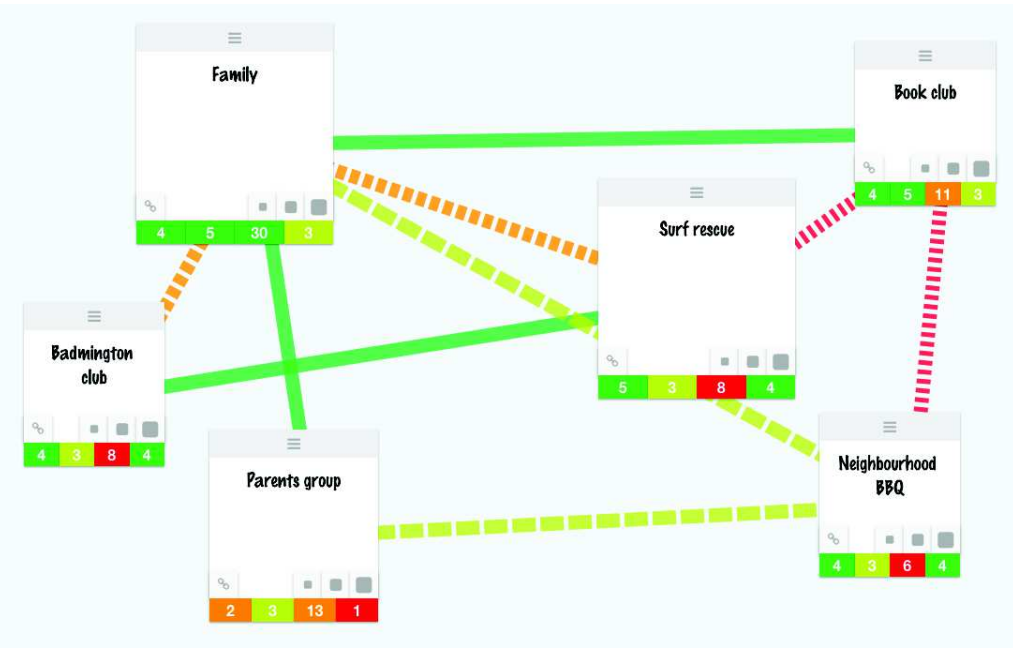

Figure 1. An example online social identity map.

\section{Research Aims}

The main goal of this research was to develop and validate an oSIM tool. This encompassed three key objectives. First, we aimed to examine whether the tool was easy to use and engaging for participants. Second, we aimed to test the reliability and validity of oSIM. Third, we aimed to assess the contextual adaptability of the tool by testing it with samples drawn from different populations.

To test its psychometric properties, we examined oSIM on a range of criteria, outlined in Table 1. The internal consistency of the tool was explored via associations between oSIM variables. Convergent validity was examined by testing for associations between oSIM variables and traditional social identity scales. Discriminant validity was examined by testing for associations between oSIM variables and theoretically unrelated constructs. We also assessed the predictive validity of oSIM, hypothesizing it should replicate associations with well-being found in the social cure literature (e.g., Haslam, Jetten, Cruwys, Dingle, \& Haslam, 2018a). Finally, contextual adaptability was assessed by examining the relationship between oSIM variables and contextually-specific outcomes that are theoretically and/or practically relevant in a particular domain (e.g., intention to continue studying for students). 
We conducted four studies, plus two additional studies reported in Supplementary Materials. All data and analysis files are available for download at this $\underline{\text { link. }}$. Study 1 evaluated user experience, reliability, and validity. Studies 2 to 4 tested the predictive validity of oSIM in different contexts and, in so doing, assessed the contextual adaptability of the tool. More specifically, because previous research has shown that having access to multiple groups and associated social identities is particularly important in the context of life transitions (e.g., Haslam et al., 2008; Iyer et al., 2009; Steffens, Cruwys, Haslam, Jetten, \& Haslam, 2016; Steffens, Gocłowska, Cruwys, \& Galinsky, 2016), Studies 2 to 4 were conducted with samples that allowed us to map different transitions across the lifespan: students transitioning from high-school to university (Study 2), women having a baby (Study 3), and retirees moving out of the workforce (Study 4).

Power analyses. Based on previous meta-analytic results showing an average correlation of $r=.25$ between multiple group memberships and well-being (across 20 independent Western samples; Chang et al., 2016), we aimed for sample sizes of at least $N=$ 160 to ensure stable correlation coefficients (Schonbrodt \& Perugini, 2013). The studies all have between $76 \%$ and $80 \%$ power to detect a medium effect size. To further ensure the robustness of the effects and inform further refinement of the tool, we conducted a metaanalysis on the results of these studies.

Sample diversity. For reasons outlined above, we aimed to test oSIM with samples drawn from populations going through different life transitions each associated with particular challenges or vulnerability. Participants were fairly homogenous in terms of ethnic and cultural background, while representing a broad cross-section of the general population in terms of age and employment (see Table 2). While greater diversity is certainly desirable - a desire that we hope to see realized soon in future research — we believe our samples are broad enough to provide preliminary tests of the reliability and validity of oSIM. 
Table 1. Criteria for assessing oSIM psychometric properties.

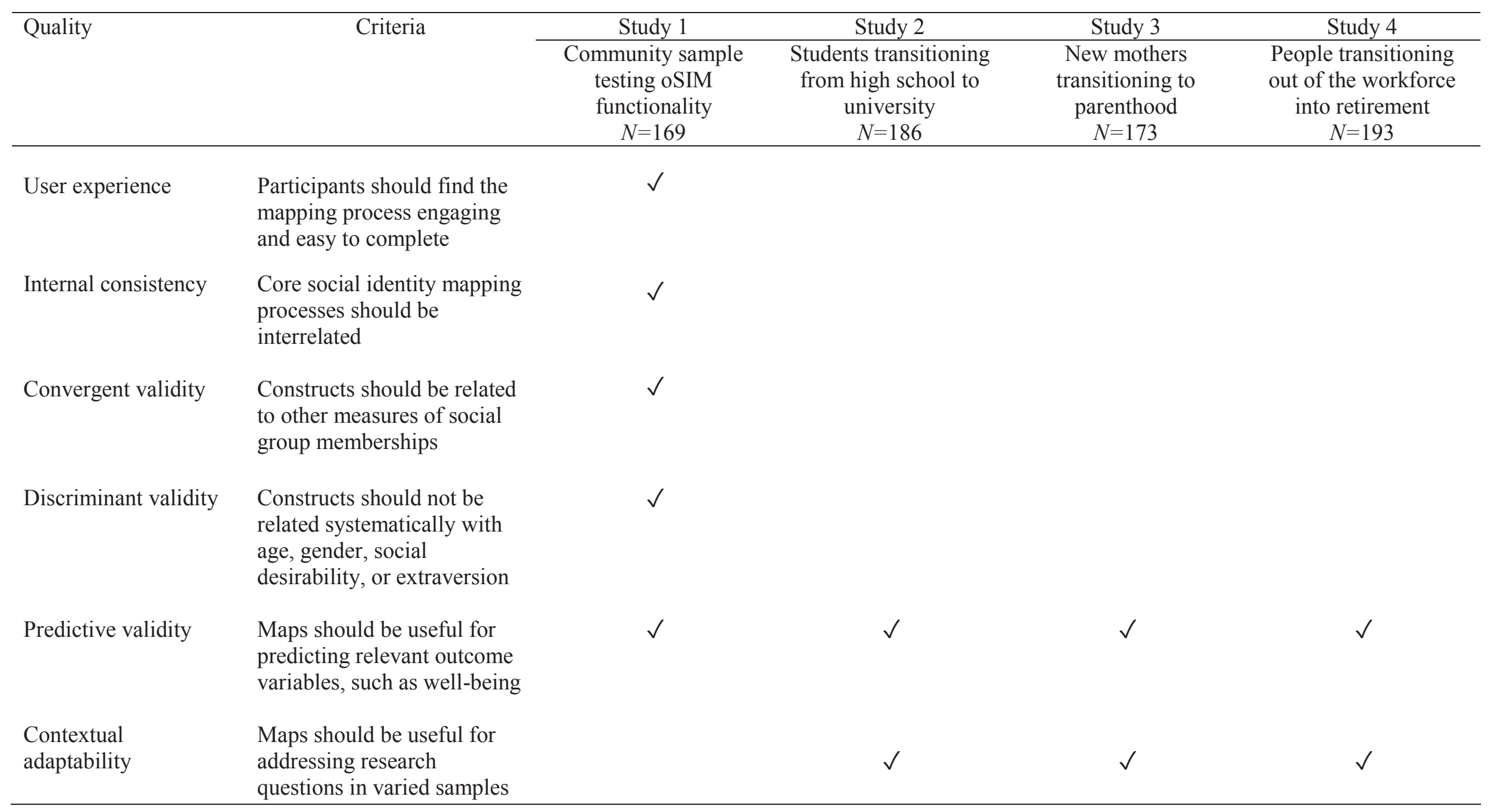


RUNNING HEAD: SOCIAL IDENTITY MAPPING ONLINE

Table 2. Demographic features of samples in Studies 1 to 4.

\begin{tabular}{|c|c|c|c|c|c|}
\hline Study & Sample & Gender & Age $(S D)$ & Employment & Ethnicity/Cultural Heritage \\
\hline 1 & Community sample & $48 \%$ female & $\begin{array}{l}M=37.76(10.50) \\
\text { Range }=21-70\end{array}$ & $\begin{array}{l}67 \% \text { full-time; } 11 \% \text { part-time; } \\
5 \% \text { casual; } 16 \% \text { unemployed }\end{array}$ & $\begin{array}{l}\text { 81\% Caucasian; } 2 \% \text { Hispanic or } \\
\text { Latino; } 8 \% \text { African American; } \\
7 \% \text { Asian; } 1 \% \text { Native American; } \\
\text { 1\% Other. }\end{array}$ \\
\hline 2 & Undergraduate students & $78 \%$ female & $\begin{array}{l}M=21.35(6.68) \\
\text { Range }=17-53\end{array}$ & $100 \%$ students & $\begin{array}{l}\text { 55\% Caucasian; 37\% Asian; 4\% } \\
\text { Indian; 3\% Chinese; } 1 \% \\
\text { European. }\end{array}$ \\
\hline 3 & New mothers & $100 \%$ female & $\begin{array}{l}M=33.44(5.60) \\
\text { Range }=21-53\end{array}$ & $\begin{array}{l}42 \% \text { full-time; } 24 \% \text { part-time; } \\
31 \% \text { Homemaker; } 3 \% \\
\text { unemployed }\end{array}$ & $\begin{array}{l}\text { 74\% Caucasian; } 4 \% \text { Hispanic or } \\
\text { Latino; } 11 \% \text { African American; } \\
\text { 11\% Asian. }\end{array}$ \\
\hline 4 & Retirees & $38 \%$ female & $\begin{array}{l}M=69.08(5.41) \\
\text { Range }=56-85\end{array}$ & $100 \%$ Retired & $\begin{array}{l}81 \% \text { Australian; } 10 \% \text { British; } 1 \% \\
\text { Chinese; } 2 \% \text { European; } 6 \% \text { other. }\end{array}$ \\
\hline
\end{tabular}




\section{Study 1}

Study 1 was designed to test the usability and validity of the oSIM interface.

Convergent validity was assessed by comparing oSIM constructs against traditional selfreport measures of social identity. Discriminant validity was assessed against gender and age, as well as social desirability and a personality measure of extraversion. We chose to assess social desirability to ensure that there was no effect of participants creating artificially 'better' social group representations, and we assessed extraversion in order to ensure that our variables of interest were not systematically related to this measure of individual difference in sociality. Predictive validity was assessed by examining associations between oSIM constructs and two measures of well-being: life satisfaction and depression. This was because, in line with the social cure literature (e.g., Haslam, Jetten, et al., 2018; Jetten et al., 2012; Jetten et al., 2017), and as outlined in the introduction, we hypothesized that oSIM could provide insight into the different social identity processes that contribute to health and well-being. Study 1 was therefore able to provide a first analysis of the significance of the distinction between the quality and the quantity of group memberships.

\section{Method}

Participants. One-hundred-and-sixty-nine adult participants were recruited from MTurk and were paid \$3 for completing the survey, which took approximately 30 minutes. Participants were US citizens and they were required to have at least a 95\% approval rate. Full descriptive statistics are provided in Table 2.

Procedure. Participants were directed to a survey in which they were asked to list their social group memberships, and to rate the importance and positivity of each. They were then directed to the oSIM interface, where they were asked to "map out their social groups". Participants could spend as little or as long as they liked working on their maps. On returning 
to the survey, they were asked a series of questions about their experience of creating the map and about their social connectedness, well-being, and personality.

\section{Measures.}

User experience. This was rated on a scale ranging from 1, strongly disagree to 5, strongly agree, and assessed (a) ease of use (five items, e.g., "I found the mapping tool simple to use"), (b) enjoyment, (two items, e.g., "I enjoyed using the mapping tool”), (c) learning (three items, e.g., "In using the mapping tool, I learnt something about myself"), (d) positive affect (two items, e.g., "Seeing my map made me feel good about myself"), (e) negative affect (two items, e.g., "Seeing my map made me feel depressed"), and (f) overall experience ("Overall, using the mapping tool was a good experience"). All scales were reliable ( $\alpha$ s ranged from .91 to .95). Participants also had the opportunity to report any difficulties or errors they encountered during the mapping process.

\section{Convergent validity.}

Group listing task. Participants completed a group listing task (Cruwys et al., 2016; Haslam et al., 2008), listing their social group memberships (up to a maximum of 10), and rating (on scale from 1, not at all to 10, very) the positivity ('How positive you feel about being member of this group?') of each. The total number of groups was calculated by summing the number of groups listed. Group positivity was calculated as the total number of groups that were rated above the mid-point for positivity.

Multiple group memberships. Participants completed a 4-item scale of multiple group membership (Haslam et al., 2008; e.g., "I belong to lots of different groups"). Responses were made on scales ranging from 1, strongly disagree to 7, strongly agree, $\alpha=.92$.

Social support. An 8-item scale measured participants' perceived levels of social support (House, Robbins, \& Metzner, 1982; e.g., "I get the emotional support I need from 
people"). Responses were made on scales ranging from 1, strongly disagree to 7, strongly agree, $\alpha=.91$.

Identity compatibility. Participants completed a 3-item measure of compatibility between their multiple group memberships. This was adapted from a measure of identity harmony previously developed by Brook, Garcia, and Fleming (2008); e.g., "On the whole, it is easy for me to be a member of different groups"). Responses were made on scales ranging from 1, strongly disagree to 7 , strongly agree, $\alpha=.83$.

\section{Discriminant validity.}

Social desirability. Participants were asked to respond with either 'True' or 'False' to ten items designed to capture their level of concern about creating a positive impression of themselves (Reynolds, 1982; e.g., "I have never deliberately said something that hurt someone's feelings"). Scores were based on summed totals.

Personality. Participants answered 20 questions designed to capture the multidimensional nature of personality (Rammstedt \& John, 2007). The focal variable of interest was extraversion, which was measured using four items (e.g., 'I see myself as someone who is outgoing'). Responses were made on scales ranging from 1, strongly disagree to 7, strongly agree, $\alpha=.91$.

\section{Predictive validity.}

Life satisfaction. Participants completed a five-item life satisfaction scale (Diener, Emmons, Larson, \& Griffith, 1985; e.g., "In most ways my life is close to ideal”). Responses were made on scales ranging from 1, strongly disagree to 7, strongly agree, $\alpha=.95$.

Depression. Participants completed the 21-item Depression, Anxiety Stress Scale (DASS; Lovibond \& Lovibond, 1995) measuring depression, anxiety, and stress, with seven items relating to each of the three constructs (Henry \& Crawford, 2005). Our analysis focused on the measure of depression (e.g. [Over the past week] "I couldn't seem to 
experience any positive feeling at all"). Responses were made on scales ranging from 1, did not apply to me at all to 4, applied to me very much. In accordance with published recommendations, scores were calculated by summing responses to all seven items and then multiplying by two. ${ }^{4}$

Social identity mapping. Participants completed their maps as described in the introduction. The key variables captured quantity and quality of group memberships: (1) quantity in terms of number of groups in participants' maps, as well as participants' perception of the amount of time spent with each of their groups (measured in terms of how many day in the average month spent interacting with the group, on a scale of 0 , no contact, to 30, every day of the month); and (2) quality in terms of participants' perceptions of their relationships with each of their groups. This second dimension involved asking participants how positive they felt about their groups, how typical or representative they felt they were of their groups, how much support they received from their groups, and how compatible participants perceived their groups to be. Participants were asked to rate positivity, representativeness and support on a scale ranging from 1 , not at all positive / representative / supportive to 10, very positive / representative / supportive (scores of 6 and above were considered above the mid-point and non-anchor numbers were unlabelled). Finally, participants rated the level of compatibility between their groups on a colour coded visual scale ranging from 1, not compatible at all as represented by a frowning face, to 4 very compatible, as represented by a smiley face. These variables were analysed in terms of a raw count of number of groups in maps, a raw count of groups rating above the mid-point for positivity, representativeness, support and time spent ${ }^{5}$, and proportion of compatible links ${ }^{6}$.

\footnotetext{
${ }^{4}$ It was decided a priori to focus on depression and that data from the other two DASS constructs (anxiety and stress) would not be examined or utilised for analysis.

${ }^{5}$ On inspecting the descriptive statistics for the oSIM variable of quantity of time spent, the numbers suggested that once a week was a suitable cut-off point to determine a group perceived to be high contact.
} 


\section{Results}

User experience. As the descriptive statistics provided in Table 3 show, participants responded positively to the social identity mapping experience. Furthermore, no participants reported any errors or difficulties in relation to any aspect of the functionality.

Table 3. Descriptive statistics for measures of user experience.

\begin{tabular}{lcccc}
\hline & Mean & $S D$ & Min & Max \\
\hline Ease of use & 4.32 & 0.84 & 1.40 & 5.00 \\
Enjoyment & 3.92 & 0.96 & 1.00 & 5.00 \\
Learning & 3.67 & 0.91 & 1.00 & 5.00 \\
Negative affect & 1.64 & 1.02 & 1.00 & 5.00 \\
Positive affect & 3.66 & 1.05 & 1.00 & 5.00 \\
Overall positive experience & 4.04 & 1.06 & 1.00 & 5.00 \\
\hline
\end{tabular}

Internal consistency. Descriptive statistics and bivariate correlations are displayed in Table 4. Participants took on average between 5 and 10 minutes to complete their social identity maps. The median number of groups depicted on each map was 5, although there was variability, with total number of groups ranging from 2 to 11 . This is very similar to the number of groups generated via the group listing task. Participants had a median of 4 positive oSIM groups, 4 oSIM representative groups, and 3 oSIM supportive groups. Most of the oSIM indices were significantly intercorrelated.

Convergent validity. Bivariate correlations provided evidence of convergent validity. Responses on the group-listing task (number of groups and number of positive groups) were positively and significantly correlated with their corresponding scores on the oSIM tool. Consistent with the idea that this measure includes elements of both quantity and quality of social group memberships, the self-report multiple group membership scale was significantly correlated with oSIM number of groups and oSIM number of positive groups. Self-reported social support was positively and significantly correlated with oSIM number of supportive

\footnotetext{
${ }^{6}$ The proportion of compatible links was calculated based on the two-interval (out of fourinterval) ratings of compatibility, in other words, this calculation was based on participants rating the connection as Compatible or Very Compatible.
} 
groups. Finally, self-report group compatibility was not significantly correlated with the oSIM proportion of compatible links between groups.

Discriminant validity. Unexpectedly, age was significantly correlated with oSIM number of groups $(r=.15, p=.049)$, oSIM number of positive groups $(r=.17, p=.027)$, oSIM number of representative groups $(r=.18, p=.021)$, and oSIM proportion of compatible links between groups in their oSIMs $(r=.17, p=.031)$. However, on closer inspection, all associations were driven by the youngest group of participants (those under 25 years old, only $8 \%$ of the sample). When this category of participants was excluded, there were no significant associations between age and any of the oSIM variables.

No significant associations were observed between gender and oSIM measures. In addition, there were no significant associations between social desirability scores and any of the oSIM measures ( $r$ s ranged from -.06 to .12; $p$ s ranged from .12 to .59 ). Finally, there were no significant associations between self-reported extraversion and any of the oSIM measures, except for number of supportive groups $(r=.17, p=.026)$.

Predictive validity. There were no significant associations between the quantityrelated oSIM variables (i.e., number of groups and number of high-contact groups) and measures of well-being, with one exception: a positive association between number of highcontact groups and life satisfaction. In contrast, there were a number of significant associations between quality-related oSIM variables and measures of well-being. Specifically, greater life satisfaction was associated with oSIM number of positive groups, oSIM number of representative groups, oSIM number of supportive groups, and oSIM proportion of compatible links. Moreover, significantly fewer symptoms of depression were associated with oSIM number of positive groups, oSIM number of representative groups, oSIM number of supportive groups, and oSIM proportion of compatible links. 
Table 4. Means, standard deviations (in parentheses), range, and bivariate correlations between group listing variables and oSIM constructs (Study 2).

\begin{tabular}{|c|c|c|c|c|c|c|c|c|c|c|c|c|c|c|}
\hline & Range & 1 & 2 & 3 & 4 & 5 & 6 & 7 & 8 & 9 & 10 & 11 & 12 & 13 \\
\hline 1. oSIM: Number of groups & $2-11$ & $\begin{array}{c}4.96 \\
(2.10)\end{array}$ & $.89^{* * *}$ & $.82^{* * *}$ & $.65^{* * *}$ & $.63^{* * *}$ & .15 & $.85^{* * *}$ & $.79^{* * *}$ & $.26^{* * *}$ & -.10 & $.24^{* *}$ & .12 & -.07 \\
\hline 2. oSIM: Number of positive groups & $0-10$ & & $\begin{array}{c}4.44 \\
(1.99)\end{array}$ & $.87^{* * *}$ & $.74^{* * *}$ & $.61^{* * *}$ & $.22^{* *}$ & $.73^{* * *}$ & $.77^{* * *}$ & $.35^{* * *}$ & .06 & $.32^{* * *}$ & $.21^{* *}$ & $-.21^{* *}$ \\
\hline 3. oSIM: Number of representative groups & $0-10$ & & & $\begin{array}{c}4.10 \\
(1.94)\end{array}$ & $.78^{* * *}$ & $.65^{* * *}$ & $.22^{* *}$ & $.68^{* * *}$ & $.71^{* * *}$ & $.33^{* * *}$ & .05 & $.34^{* * *}$ & $.22^{* *}$ & $-.20^{* *}$ \\
\hline 4. oSIM: Number of supportive groups & $0-10$ & & & & $\begin{array}{c}3.40 \\
(1.81)\end{array}$ & $.57^{* * *}$ & $.19^{*}$ & $.54^{* * *}$ & $.62^{* * *}$ & $.41^{* * *}$ & $.25^{* * *}$ & $.39^{* * *}$ & $.25^{* * *}$ & $-.20^{* *}$ \\
\hline 5. oSIM: Number of high-contact groups & $0-9$ & & & & & $\begin{array}{c}2.66 \\
(1.83)\end{array}$ & .13 & $.53^{* * *}$ & $.52^{* * *}$ & $.27^{* * *}$ & .08 & $.29^{* * *}$ & $.16^{*}$ & -.04 \\
\hline 6. oSIM: Proportion of compatible links & $0-1$ & & & & & & $\begin{array}{c}0.85 \\
(0.26)\end{array}$ & .15 & .15 & .09 & $.15^{*}$ & .13 & $.16^{*}$ & $-.16^{*}$ \\
\hline 7. Group list: Number of groups & $1-10$ & & & & & & & $\begin{array}{c}5.33 \\
(2.51)\end{array}$ & $.92^{* * *}$ & $.29^{* * *}$ & -.05 & $.22^{* *}$ & .11 & .00 \\
\hline 8. Group list: Number of positive groups & $1-10$ & & & & & & & & $\begin{array}{c}4.77 \\
(2.34)\end{array}$ & $.40^{* * *}$ & .11 & $.31^{* * *}$ & $.16^{*}$ & -.09 \\
\hline 9. Self-report: Multiple group membership & $1-7$ & & & & & & & & & $\begin{array}{c}4.40 \\
(1.46)\end{array}$ & $.44^{* * *}$ & $.70^{* * *}$ & $.40^{* * *}$ & $-.32^{* * *}$ \\
\hline 10. Self-report: Social support & $1-7$ & & & & & & & & & & $\begin{array}{c}4.84 \\
(1.19)\end{array}$ & $.49^{* * *}$ & $.55^{* * *}$ & $-.50^{* * *}$ \\
\hline 11. Self-report: Group compatibility & $1-7$ & & & & & & & & & & & $\begin{array}{c}5.03 \\
(1.07)\end{array}$ & $.53^{* * *}$ & $-.42^{* * *}$ \\
\hline 12. Life satisfaction & $1-7$ & & & & & & & & & & & & $\begin{array}{c}4.75 \\
(1.60)\end{array}$ & $-.69^{* * *}$ \\
\hline 13. Depression & $14-54$ & & & & & & & & & & & & & $\begin{array}{c}20.82 \\
(10.48)\end{array}$ \\
\hline
\end{tabular}

Note. ${ }^{* * *} p<.001,{ }^{* *} p<.01, \stackrel{*}{p}<.05$. 


\section{Discussion}

Study 1 confirmed that oSIM functioned successfully and that participants found the mapping process easy and enjoyable. In a short space of time, participants created data-rich maps representing the quantity and quality of their social group memberships and the compatibility between these group memberships.

Evidence of convergent validity was provided by significant associations between the oSIM constructs and traditional self-report measures of social identity. The one exception was the lack of association between the proportion of compatible groups as measured by the oSIM and identity compatibility as assessed by Brook and colleagues' (2008) self-report identity compatibility scale. There may be a number of reasons for this lack of correspondence. First, it is important to note that Brook et al.'s scale is unvalidated. Moreover, in our estimation, only one item in this scale truly assesses group compatibility in the way intended in the oSIM procedure ("There is harmony between the various groups I am a member of"). When we inspect the association between this single item and oSIM compatibility, the correlation becomes slightly stronger $(r=.20, p<.001)$. In addition, it may be that the generally low correlation reflects the difference between a person's global perception of identity compatibility as measured by the identity compatibility scale, and the more fine-grained measure of group-level compatibility between pairs of groups that oSIM provides. We believe these possibilities speak to the need for more research on group compatibility - a goal which oSIM will facilitate. Indeed, given the current dearth of measures available in the literature, oSIM is uniquely placed to revitalize this research area.

Evidence of oSIM's discriminant validity was provided by limited association between oSIM constructs and age or gender (and none after participants under 25 had been removed from the sample). It is also worth noting that this age effect was not replicated in later studies (i.e., Studies 2, 3, and 4) and so we refrain from interpreting this further. 
Moreover, there were no significant associations between the oSIM indices and social desirability or extraversion, indicating that responses on the oSIM are unlikely to reflect either people's desire to make a good impression, or their inclination to interact with people in general.

This study also provided evidence of predictive validity in so far as the quality of social group memberships captured by participants' maps was consistently associated with greater well-being, as measured by greater life satisfaction and lower depression. This was true for all measures of quality, including number of positive groups, number of representative groups, number of supportive groups, and proportion of compatible links between groups. There were however, no consistent associations between well-being and measures of the (mere) quantity of social group memberships. These data provide the first evidence that the tool can provide insights capable of informing ongoing theoretical debates - suggesting that when it comes to group memberships and well-being, the phrase 'the more the merrier' should rather be re-conceptualized as 'the more meaningful the merrier' (e.g., in ways suggested by the multiple identities hypothesis: Haslam, Jetten, et al., 2018; Jetten et al., 2017). This issue was investigated further in Studies 2, 3, and 4.

Of course, Study 1 was cross-sectional, and was therefore unable to provide insight into the causal direction of the relationships uncovered. Studies 2 to 4 were designed to address this issue by using longitudinal and pseudo-longitudinal designs. In addition, we aimed to broaden the scope of the oSIM by assessing its predictive power in a range of different contexts.

\section{Studies 2, 3 and 4}

Having established the psychometric properties of oSIM in Study 1, three further studies were designed to test its predictive validity and contextual adaptability. To this end, we targeted people at different stages in life, focusing on life transitions that previous 
research has found to be challenging for health and well-being: starting tertiary study (Study 2; e.g., Iyer et al., 2009), motherhood (Study 3; e.g., Seymour-Smith et al., 2017a), and retirement (Study 4; e.g., Steffens et al., 2016).

Because the goal of this paper is to validate oSIM across a range of contexts, we took the approach of analyzing and reporting results of Studies 2 to 4 in a pooled meta-analytic format. This allowed us to examine broader trends in the degree to which oSIM constructs predicted well-being outcomes. In addition, it allowed us to extract higher-order constructs from the data that combine the oSIM elements that most consistently predicted well-being. To identify broader trends, we took a meta-analytic approach to examine the extent to which oSIM variables were consistently associated with well-being (exploiting the full range of data from Studies 2 to 4). We then used these findings to generate an index for groups that combined the most predictive oSIM elements.

To validate these new indices of high-quality groups (which we term supergroups), we used the longitudinal and pseudo-longitudinal designs in Studies 2 to 4 to predict outcomes over time. Because we created the supergroup index based on oSIM relationships with well-being, it would be redundant to use this index to predict changes in well-being. For this reason, we used the new supergroup index to predict a different outcome variable adjustment to new life circumstances. This is important not only because it shows the predictive validity of the supergroup index in relation to a novel outcome, but also because ability to adjust to new challenges constitutes a component of resilience (Bonanno, 2004; Bonanno \& Diminich, 2013). We therefore applied the supergroup index to predict adjustment to the domains explored in the studies: university, motherhood, and retirement.

\section{Sample Details}

Study 2 was conducted with a sample of students transitioning from high school to university study. This has been identified as a uniquely stressful life experience (Galatzer- 
Levy, Burton, \& Bonanno, 2012; Yeager, Romero, et al., 2016). Indeed, there is growing concern about the high rate of attrition among tertiary students, and researchers are increasingly interested in the question of how to successfully transition into university (Daempfle, 2003; Krause \& Coates, 2008). In this context, university identification has been shown to be a protective factor, predicting positive student attitudes, well-being, and better learning (Libbey, 2004; Smyth, Reynolds, Grace, Platow, \& Mavor, 2015). Given these findings, we anticipated that oSIM could shed light on the relationships between broader social identity constructs and students' well-being, as well as commitment to their educational journey. We assessed well-being in the form of life satisfaction and depression at two time points over students' first semester of study. In addition, we included a variable designed to assess positive adjustment to the new context: intention to continue studying at university (Bean \& Metzner, 1985; Chartrand, 1992).

Study 3 assessed oSIM in the context of women undergoing a different life transition — that associated with motherhood. For many parents, the birth of a child is both a uniquely wonderful and intensely disruptive experience (e.g., Bugental et al., 2002). Failure to adapt constructively to this new role has a number of negative consequences for parent and child (Belsky, 1984). For example, research has demonstrated a link between the mother-infant relationship and postnatal depression (Murray, Fiori-Cowley, Hooper, \& Cooper, 1996). Speaking to the role of social factors in this process, recent social psychological research has suggested that identity continuity can play a protective role during the postpartum period (Seymour-Smith, Cruwys, Haslam, \& Brodribb, 2017b). In this study we examined whether oSIM could provide a fine-grained analysis of the social identity processes that support successful adjustment to motherhood. We again assessed well-being in the form of life satisfaction and depression, and assessed adjustment to this new life circumstance in the form of the mother's self-reported attachment to her child (Anan \& Barnett, 1999; Booth, Rubin, \& 
Rose-Krasnor, 1998; Fonagy, Steele, \& Steele, 1991).

Study 4 was conducted with a sample of people who had recently transitioned to retirement. We chose to focus on this domain because moving from a lifetime of work into retirement is recognized as a transitional moment in life often fraught with complex role and identity adjustments (e.g., Kahn, R 1979. Langer \& Rodin 1978, Schulz 1978). Indeed, models of retirement now recognize the need to feel meaningfully connected with other people as a way of protecting against the health risks that this life transition may pose (Forster \& Morris, 2012; Haslam, Steffens, et al., 2018; Lam et al., 2018; Steffens, Cruwys, et al., 2016). In this context, we investigated whether oSIM captured aspects of identity that were relevant to, and therefore helped predict, well-being within this population. In addition to assessing well-being in the form of life satisfaction and depression, we assessed adjustment in the form of self-reported adjustment to retirement.

\section{Method}

Participants and procedure. Demographics for all studies are provided in Table 2.

Study 2. One-hundred-and-eighty-six first year Australian first-year undergraduate psychology students were recruited as part of a psycho-educational intervention study, and participants received partial course credit in exchange for their involvement ${ }^{7}$. Students completed a survey and a social identity map at the start of their first semester at university (T1), and again at the end of the semester $(\mathrm{T} 2)^{8}$.

Study 3. An online community sample of 173 mothers who had given birth in the last 5 years were recruited for this study via MTurk. On average, our sample of mothers had given birth to two children. All questions related to participants' most recent child.

\footnotetext{
${ }^{7}$ This study was originally designed as a randomized control trial with three conditions; the full dataset is reported elsewhere (Bentley, Greenaway, Haslam, \& Halsam, 2019 (in preparation), contact the corresponding author for details).

${ }^{8}$ Due to the particular design of this study, support received was not included as a measure. Supergroups in Study 2 are therefore calculated as the number of groups that score above the mid-point for positivity and representativeness and have at least 50\% compatible links.
} 
Participants were paid $\$ 3$ for participating. They were recruited through a pre-screener survey on MTurk. Criteria for participation were: being female; a parent; and having given birth in the last five years. Participants completed the self-report measures before being directed via an on-screen link to the oSIM tool. This study took a pseudo-longitudinal approach, whereby participants were asked to think back to 12 months before the birth of their most recent child and to create a visual representation of their social group memberships at that time. Once complete, participants were then asked to create another map representing their social group memberships in the present day.

Study 4. An online community sample of 193 retirees were recruited for this study using an Australian Qualtrics panel data set. Participants came from a range of backgrounds, from legal to education, from commercial to farming, and the median length of time since retirement was 8 years. Participants were paid for their participation in the survey according to the payment structure deployed by the panel data provider. Participants were recruited through a pre-screener survey within the Qualtrics panel sample. Criteria for inclusion were being an Australian resident and being formally retired from one's career work. Participants completed the self-report measures before being directed to the oSIM tool. As with Study 4, this study deployed a pseudo-longitudinal design — participants were asked to create a visual representation of their social group memberships as they are in the present-day (postretirement). After this, they were asked to think back to 12 months before their retirement and create a visual representation of their social group memberships as they were at that time.

They then completed demographic questions, were debriefed and paid.

\section{Measures}

Well-being. Life satisfaction in all studies was measured using the satisfaction with life scale by Diener and colleagues (1985) as described in Study 1. Depression was assessed using three measures, each of which has been validated across different contexts and 
countries. These depression measures were chosen to be appropriate for each population. In Study 2, depression was assessed using the depression subscale of the DASS inventory by Lovibond and Lovibond (1995) as described in Study 1. The DASS scale is a brief depression measure and as such was appropriate for a student population in which the focus was not clinical. In Study 3, depression was assessed using the 9-item Patient Health Questionnaire (Spitzer, Kroenke, \& Williams, 1999), which includes items corresponding to the diagnostic indicators of depression (e.g., "I have little interest or pleasure doing things"), and was scored on a scale ranging from 1, did not apply to me at all to 4, applied to me nearly every day. This scale, which is often used as a diagnostic check list, was thought to be relevant for new mothers who are at an elevated risk of depression (Gjerdincjen, Crow, McGovern, Miner, \& Center, 2009). In Study 4, depression was assessed using the CES-D scale 8-item depression scale (Andresen, Malmgren, Carter, \& Patrick, 1994; Van de Velde, Levecque, \& Bracke, 2009) e.g., "In the last week I have felt sad", which was scored on a scale ranging from 1, rarely or none of the time to 4, most of the time. This measure of depression is more appropriate for this sample because it is more widely used with older people and there is evidence of its validity in this group (Turvey, Wallace, \& Herzog, 1999; Beekman, Deeg, Van Limbeek, Braam, De Vries, \& van Tilburg, 1997).

Adjustment. Participants in all studies completed measures that indexed adjustment to challenging life circumstances. These were intentions to continuing studying (Study 2), attachment to child (Study 3), and adjustment to retirement (Study 4).

In Study 2, participants completed a nine-item scale measuring intention to continue studying at university (adapted from Vogel \& Human-Vogel, 2016; e.g., "I intend to continue studying at [university name] after this semester"). Responses were made on scales ranging from 1, strongly disagree to 7 , strongly agree, $\alpha_{\mathrm{T} 1}=.73, \alpha_{\mathrm{T} 2}=.75$. In Study 3 , participants completed a 15-item scale measuring attachment to the child they most recently gave birth to 
(adapted from Pianta \& Steinberg, 1992; e.g., "I share an affectionate, warm relationship with my child"). Responses were made on scales ranging from 1, definitely does not apply to 5, definitely applies, $\alpha=.84$. In Study 4, participants completed a 12-item scale measuring adjustment to retirement (Wells, de Vaus, Kendig, Quine, \& Peteralia, 2006; e.g., "Retirement has been better than expected"). Responses were made on scales ranging from 1, do not agree at all, to 5, agree completely, $\alpha=.88$.

Social identity mapping. Participants in all studies completed their maps as described in Study 1, with one exception: number of supportive groups was not assessed in Study 2.

\section{Results}

Predictive validity. Bivariate correlations for each study are presented in Tables A1 to A3 (Appendix 3). ${ }^{9}$ Overall, these revealed a range of positive associations between specific oSIM indices and outcome variables. In particular, within the student population there was evidence at both time points of significant associations between number of positive and representative groups and well-being (particularly life satisfaction), as well as student intentions to continue studying. For mothers, there was evidence of significant relationships between quality of group memberships and depression, and evidence that group compatibility was particularly predictive of life satisfaction, depression and attachment to child. For retirees there was again evidence of the importance of quality of group memberships for life satisfaction, as well as for adjustment to retirement. There was also some evidence of the role of overall quantity of group memberships within these studies: for students this was significantly associated with intention to study at both time points, and for retirees this was significantly associated with life satisfaction, but there were no such associations for mothers. To further examine the consistency of these relationships, we conducted a meta-analysis.

\footnotetext{
${ }^{9}$ It is worth noting that in Study 3 - our only truly longitudinal design - Time 1 oSIM constructs were all significantly correlated with their Time 2 counterparts, suggesting at least moderate stability (i.e., test-retest reliability).
} 
Meta-analysis. To assess the robustness of these associations across the contexts captured by the three studies, we conducted a meta-analysis drawing on their findings as well as those from Study 1 to assess how oSIM indices were associated with life satisfaction and depression. We conducted this meta-analysis using the $\mathrm{R}$ metafor package (Viechtbauer, 2010) with a random effects model, transforming the raw correlation coefficients in each study using the Fischer's $r$-to- $z$ transformation. For Study 2, which included two measures of each outcome variable, we averaged the correlations across the time points as recommended by Polanin, Hennessy, and Tanner-Smith (2017). For Studies 3 and 4, in which participants created two social identity maps, but only one of each well-being outcome, we included correlations using the maps that represent people's current social group memberships.

Results of the meta-analysis are presented in Table 5. These point to significant overall associations between well-being (i.e., both life satisfaction and depression) and four of the six oSIM indices: number of positive groups, number of representative groups, number of supportive groups, and number of compatible links between groups. The correlations are small (e.g., number of compatible links) to moderate in magnitude (e.g., number of positive groups). Overall, and consistent with the trends observed in each study, these indicators all map onto the quality of group memberships rather than their quantity.

Higher-order oSIM constructs. A further feature of oSIM is that it is possible to consolidate information about social identity processes in order to provide an empirical ‘recipe' for what makes a particularly effective group. To this end, we computed what we term a supergroup index, based on the oSIM indices that most consistently predicted wellbeing. This index was calculated as the number of groups that scored above the mid-point on all four quality indicators: positivity, representativeness, and support, and that had a majority (i.e., over 50\%) of compatible links to other groups (see Table 6 for study means). Because we collected longitudinal and pseudo-longitudinal data in Studies 2 to 4, we were able to 
apply this new supergroup index to assess whether changes in these indicators of group memberships predicted psychological change. This also allowed us to establish whether this higher-order index of high-quality social group memberships, as generated by oSIM, can predict change in relevant outcomes over time. In particular, we assessed whether increases in the number of supergroups in a person's social identity map predicted improvements in adjustment to challenging life circumstances. We did this to model not only the relationship between our supergroup index and resilience over time, but also to show the capacity of this index to predict novel outcomes above and beyond well-being.

In conducting analyses to assess the impact of supergroups on adjustment over time, we took a mixed effects approach that pooled Studies 2 to 4 and modelled the variance due to differences in study design. This approach was considered appropriate given that we made no specific a priori predictions about how the associations would differ between the various contexts. Instead, in all studies we simply predicted that supergroups would show beneficial associations with adjustment. In addition to improving statistical power, this approach has the benefit of improving inferences about generalizability of the findings: psychologists often fail to account for features of study designs when drawing generalizable conclusions (Judd, Westfall, \& Kenny, 2012). Thus, rather than analyzing similar studies separately, we analyzed a pooled dataset that included a random intercept for study, so that results are not contingent on the specific design that each used. This analysis follows the logic of random effects meta-analysis, where study effects are treated as random (Cooper \& Patall, 2009), while acknowledging that each study may represent a different true effect size (due to differences in context, etc.). This approach allows us to generalize results to un-sampled contexts, just as researchers seek to generalize to un-sampled participants (Judd et al., 2012). 
Table 5. Meta-analysis of associations between oSIM variables and well-being across Studies 1 to $4(N=721)$.

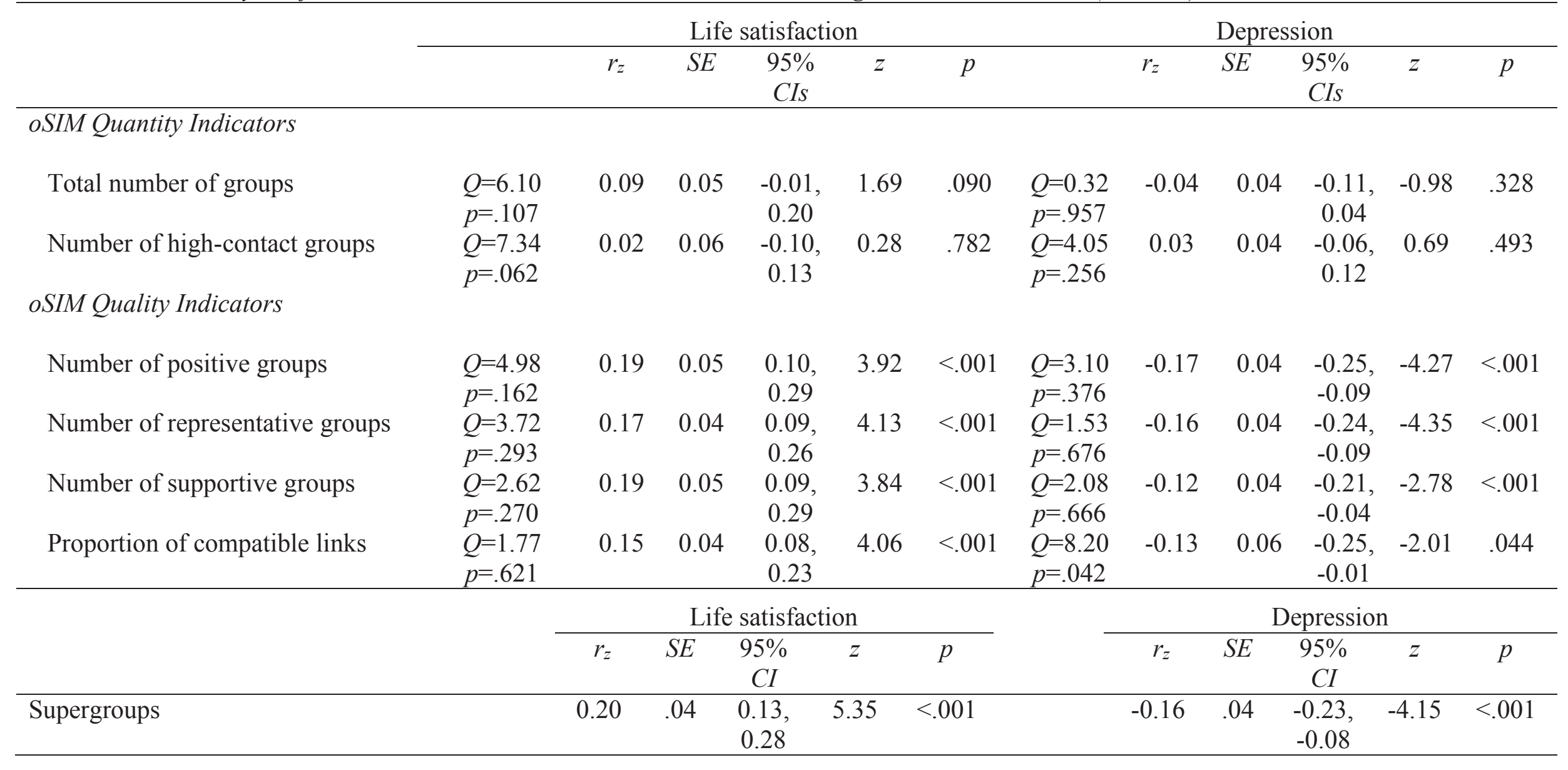

Note. $r_{z}=$ average effect size assessed by Fischer transformed correlations. $S E=$ standard error. $95 \% C I S=95 \%$ confidence intervals. Supergroups are calculated as the number of groups that score above the mid-point on all four quality indicators: positivity, representativeness, and support, and that have a majority (i.e., over $50 \%$ ) of compatible links to other groups. 
Table 6. Descriptive statistics for supergroups across Studies 1 to 4.

\begin{tabular}{lcccc}
\hline & Mean & $S D$ & Min & Max \\
\hline $\begin{array}{l}\text { Study 1 } \\
\quad \text { Supergroups }\end{array}$ & 2.47 & 1.80 & 0.00 & 10.00 \\
Study 2 & & & & \\
$\quad$ Time 1 Supergroups & 2.26 & 1.64 & 0.00 & 6.00 \\
$\quad$ Time 2 Supergroups & 2.76 & 2.14 & 0.00 & 10.00 \\
Study 3 & & & & \\
$\quad$ Past Supergroups & 1.27 & 1.08 & 0.00 & 7.00 \\
$\quad$ Present Supergroups & 1.40 & 1.39 & 0.00 & 8.00 \\
Study 4 & & & & \\
$\quad$ Past Supergroups & 0.96 & 1.15 & 0.00 & 6.00 \\
Present Supergroups & 0.77 & 1.07 & 0.00 & 5.00 \\
\hline
\end{tabular}

Table 7. Description of model specifications for hierarchical multiple regression analyses conducted in Studies 2 to 4.

\begin{tabular}{lll}
\hline & \multicolumn{1}{c}{ Fixed effects } & \multicolumn{1}{c}{ Random effects } \\
\hline $\begin{array}{l}\text { Pseudo-longitudinal analyses } \\
\text { Null model }\end{array}$ & None & Random intercept of study \\
Step 1 & Time 1 supergroups & Random intercept of study \\
Longitudinal analyses & Time 2 supergroups & Random intercept of study \\
Null model & None & \\
Step 1 & Time 1 outcome variable & Random intercept of study \\
& Time 1 supergroups & \\
Step 2 & Time 2 supergroups & Random intercept of study \\
\hline $\begin{array}{l}\text { Description of R code for analyses in Studies 2-4. Full code is available on the OSF at } \\
\text { https://osf.io/eyhb2/?view only=23b90ce2449648c9a7396ca8e706584e. }\end{array}$
\end{tabular}

Pseudo-longitudinal analyses. We first conducted analyses that we termed 'pseudolongitudinal' because, with the exception of Study 2 , the designs only sampled adjustment at one point in time. That is, in Studies 3 and 4, participants created present-day social identity maps and recreated their social identity maps as they were in the past then reported on current 
levels of adjustment. This means that we cannot control for past levels of this factor when assessing the impact of change in supergroups over time, which is a requirement for truly longitudinal designs. Nevertheless, we collected longitudinal data in Study 2 and so we report the analyses that isolate this study separately below.

Table 7 outlines the order in which variables were entered in the pseudo-longitudinal and longitudinal analyses. For the pseudo-longitudinal analyses, mixed-effects models were implemented with the lme4 R package (Bates, Maechler, Bolker, \& Walker, 2015), applying Satterthwaite-approximation tests to calculate $p$-values (Kuznetsova, Brockhoff, \& Christensen, 2017). In Step 1, we modelled fixed effects of Time 1 supergroups. ${ }^{10}$ In Step 2, we modelled fixed effects of Time 1 supergroups and Time 2 supergroups. We included a random intercept for study in both steps. These models were used in predicting adjustment in each domain (i.e., intention to continue studying for students in Study 2; attachment to child for mothers in Study 3; adjustment to retirement for retirees in Study 4).

The model at Step 1 did not account for a significant amount of variance in Time 2 adjustment, $R^{2}<.01, \chi^{2}(1)=2.44, p=.119$, indicating that Time 1 number of supergroups was not a significant predictor, $\beta=.03, p=.122$. The model at Step 2 was significantly different from the model at Step $1, R^{2}=.01, \chi^{2}(1)=11.01, p<.001$, with Time 2 supergroups predicting better adjustment among students, mothers, and retirees $(ß=.06, p<$ $.001)$.

Longitudinal analyses (Study 2 only). To examine whether the above pseudolongitudinal analyses replicate while taking advantage of Study 2's true longitudinal design, we conducted a series of hierarchical regression analyses on intentions to continue studying. At Step 1, we regressed Time 2 intentions onto its Time 1 counterpart as well as Time 1 supergroups. At Step 2, we regressed Time 2 intentions onto Time 2 supergroups along with

\footnotetext{
${ }^{10}$ To obtain an indication of model significance we compared Step 1 to a null model that included only the random intercept for study (see Table 7).
} 
Time 1 intentions and Time 1 supergroups. Conceptually, this tests whether changes in number of supergroups predicts change in intentions to continue studying over time.

The model at Step 1 accounted for a significant amount of variance in Time 2 intentions to continue studying, $R^{2}=.40, F(2,166)=55.15, p<.001$. Time 1 study intentions was a significant unique predictor $(\beta=.63, p<.001)$, although Time 1 number of supergroups was not $(ß=-.03, p=.419)$. The model at Step 2 was significant, $R^{2}=.44, F$ $(3,161)=41.93, p<.001$, with Time 2 number of supergroups predicting increases in intention to continue studying $(\beta=.09, p=.003)$.

\section{Discussion}

The foregoing meta-analysis allowed us to ascertain the aspects of a person's social group memberships that were consistently associated with the two well-being outcomes that we tracked across Studies 1 to 4: life satisfaction and depression. Throughout these studies, there was evidence that four oSIM constructs were consistently associated with greater wellbeing: number of positive groups, number of representative groups, number of supportive groups, and number of compatible links between groups.

We then used our meta-analytic findings as a basis for abstracting the higher-order construct of a supergroup (a group rated above the midpoint on positivity, representativeness, support, and compatibility). Doing so allowed us to investigate the implication of changes in a person's supergroups over time on adjustment to a range of life challenges. This investigation revealed that increases in these high-quality groups were predictive of domainspecific psychological adjustment, including intentions to continue studying, attachment to one's child, and adjustment to retirement.

These findings have three important implications. First, they provide strong and consistent evidence of the predictive validity of oSIM. Second, they demonstrate the tool's contextual adaptability — across three distinctly different contexts (university students, new 
mothers, and retires) we see evidence of the tool's capacity to capture significant relationships between social identity processes and well-being, as well as outcomes that are indicative of resilience and adjustment to challenge. Third, by looking at the effect of change in group memberships over time — and particularly increases in supergroups — these findings point to the potential for oSIM to furnish researchers and practitioners with a body of data that allows them to predict positive outcomes in the face of a wide range of stressful life circumstances.

\section{General Discussion}

This paper introduced online Social Identity Mapping, a novel tool for mapping the multidimensional nature of social identity. The tool provides an interactive approach to assessing a range of processes relevant to social identity theorizing, including indicators of group membership quantity and quality. It does this in a way that keeps agency with participants, and does not place a theoretical burden on researchers to choose the "right" referent group for a population of participants about whom one wishes to ask questions related to social identity. Instead, participants themselves select and reflect on the groups that are most relevant to their daily lives. Moreover, oSIM is versatile and can be adapted to a

\section{variety of applied contexts, as we did here to investigate social group memberships in} community, academic, parenting, and retirement contexts.

In these different contexts, we found evidence that oSIM was reliable and valid, showing acceptable internal and test-retest reliability as well as convergent and divergent validity. In addition, oSIM proved capable of predicting psychological outcomes both crosssectionally and over time. In particular, oSIM constructs were associated with well-being in the form of life satisfaction and depression. This was despite methodological variation in measures of well-being — while life satisfaction was measured in the same way across studies, depression was measured using a range of different validated scales. Furthermore, 
oSIM constructs predicted resilience in the form of intentions to continue studying, attachment to one's child, and adjustment to retirement. In this way, the information imparted by oSIM presents researchers with opportunities to capture the nuances of group memberships and their associated social identities in action.

\section{Methodological, Theoretical, and Practical Implications}

The oSIM tool is methodologically groundbreaking. Until now, the complex and connected nature of social identity has been hard to capture in a holistic sense - with researchers relying on pre-defined scales to measure aspects of group memberships and social identities (typically one at a time) that respondents may (or may not) consider personally important. The process of social identity mapping provides a way through this methodological impasse. For not only does the mapping process allow participants to define and report their own group memberships as they build their maps; it also allows them to represent the relationships between these groups and revisit these relationships at different time points to track their evolution over time.

Informing identity benefits. In addition to its methodological advancements, oSIM is also capable of making a significant contribution to theory. The first of these theoretical contributions is its ability to shed light on identity benefits - that is, what it is about social connections that is beneficial for health and well-being. For example, oSIM has been shown to be capable of contributing to ongoing debates in various literatures as to whether quantity or quality of social connections is most predictive of health and well-being outcomes. Indeed, our results provide evidence that quantity alone is of limited use when it comes to predicting well-being. However, they show that quality - having positive, representative, supportive and compatible groups in one's life - is associated with better well-being, including greater life satisfaction and lower depression. These findings are informative for a range of literatures, including epidemiological research (Cassel, 1976), social network studies 
(Fischer, 1982), and work on social engagement (Rook, 1990), that have all weighed in on the quantity vs. quality debate.

The oSIM tool also allowed us to look for patterns of group membership that may be more or less psychologically beneficial. For instance, we found that uniformly high-quality group memberships (i.e., those that are experienced as particularly positive, supportive, representative and compatible) appear to be psychologically important. The presence of these supergroups in participants' maps predicted resilience across time for a range of different populations. An intriguing question for future research is the degree to which supergroups must be related to a given context for psychological benefits to emerge. For example, some research has suggested there may be particular benefit to improving social connections within a given challenging environment (e.g., educational groups when transitioning to university; Yeager et al., 2016). Other work suggests that it is simply social connections in general, regardless of their link with a particular environment, that must increase for well-being to be supported (Walton et al., 2015). For now, it seems likely that this new source of data in oSIM can be used to better understand - and then work actively to enhance - the specific social psychological determinants of health and well-being. In this way, oSIM provides researchers and practitioners with a means of identifying (and representing) the functional aspects of group memberships, in ways that focus efforts to bring about psychological change. Of course, deployment of oSIM is not restricted to the health domain, and could profitably be used to investigate a range of processes that are of interest to social psychologists (e.g., intergroup relations; small group processes; social identity threat, etc.) However, in this line of work we have shown the value of oSIM in helping to understand the social factors that structure psychological health, thus contributing to a burgeoning social cure literature (Haslam et al., 2018, Jetten et al., 2012). Beyond social identity work, the affordances of oSIM can also be applied to help answer a variety of open theoretical 
questions, including the impact of identity differentiation versus integration on health and

well-being (e.g., Brown \& Rafaeli, 2007) and the evolution of identities across the lifespan

(e.g., Carstensen, 2006.

To take the values affirmation literature as a case study, oSIM has the potential to help researchers better understand its underlying processes. For example, researchers have long been interested in the concept of positive self-expansion as an explanation for why values affirmation processes are beneficial for psychological health (e.g., Critcher \& Dunning, 2015; Gresky et al., 2005; Walton et al., 2012). Values affirmation is hypothesized to expand the self-concept in three main ways: 1) by connecting the self to other identities, 2) by connecting the self to valued other people, and 3) by connecting the self to future identities (Walton, Paunesku, \& Dweck, 2012). Empirical evidence for these processes to date is relatively indirect, yet as a behavioral measure of the expansiveness of one's (social) self, oSIM is well-placed to inform this theorizing. This is because the oSIM tool offers a novel method of visualizing connections of the self to other valued identities and people. Indeed, in this case, people actually draw links between different groups to represent their compatibility or incompatibility. The oSIM tool is also well placed to capture people's vision of future identities. Indeed, oSIM could be used to create a current map and a future map that represents a desired version of the self. We hypothesize that such a process could also engender a growth mindset (e.g., Carr, Dweck, \& Pauker, 2011; Yeager, Trzesniewski, \& Dweck, 2011) in which people come to see their social landscape as changeable rather than static.

Informing identity change. In addition to highlighting identity benefits, oSIM is capable of providing insight into drivers and processes of identity change. For example, our data suggest that it is the degree to which people increase high-quality group memberships over time that is most predictive of beneficial well-being outcomes. This helps to advance 
theory in relation to the Social Identity Model of Change (Haslam et al., 2019; Jetten \&

Pachana, 2012), which until now has emphasized the maintenance of group memberships as

well as acquisition of new group memberships as a protective factor. Contrary to part of this

hypothesis, we find that people who do not change their supergroup memberships in a

positive direction are at risk of not showing well-being gains. Because it allows participants

to represent their group memberships as they see them, oSIM also has potential in

contributing to areas of research in which visualization of identity change would be useful.

Informing identity intervention. A further possibility that we have only begun to

explore is that oSIM may be used as in intervention in its own right. This is because oSIM is

a strong visual reminder of people's social connectedness, perhaps made more powerful by

virtue of the fact that participants complete the activity from their own perspective and of

their own volition. Such a process is reminiscent of the saying-is-believing principle, a subtle

technique in which people are encouraged to internalize a particular perspective by

advocating for the benefits of that perspective in a way they see fit (Walton et al., 2015).

Similarly, participants engage with oSIM in a free and autonomous way, with no time limit

placed on their participation and no insistence on which groups must be represented.

We ran a supplementary study to test this hypothesis (reported in Supplementary

Materials). In this study we counterbalanced the order of presentation of oSIM and traditional

self-report measures of social identity. Relative to traditional measures, oSIM did not make

people more aware of their group memberships. However, it did make people feel more in

control of their group memberships and made them more aware of connections between their

groups. Not trivially, oSIM was also more interesting for participants than completing

traditional self-report measures. And even more pointedly, oSIM significantly increased well-

being measures in the form of life satisfaction and state positive affect. These preliminary

findings speak to the potential for oSIM to be used as an intervention to help people feel 
more agentic and connected. That said, we maintain that it may be most useful when embedded within a developed intervention framework that works further to support and enhance positive social connections, such as that being developed in the social identity or social belonging literatures (e.g., Haslam et al., 2016; Walton \& Cohen, 2011; Walton, Logel, Peach, Spencer, \& Zanna, 2015).

In addition to having theoretical and practical implications for ongoing issues in the field, oSIM has potential to help develop future research agendas. The concept of a supergroup raises the possible existence of an infragroup - a group characterized by its toxicity through high levels of negativity, low prototypicality, low support, and high incompatibility. Such a construct might be applied to help explain situations of intergroup antagonism, such as racial or class prejudice, or negative health consequences observable in the inverse of social cure work - the social curse literature (Muldoon, Walsh, Curtain, Crawley, \& Kinsella, 2018). The prevalence of infragroups in our data was too low to investigate this intriguing possibility. However, social curse research is typically conducted in the context of stigmatized or vulnerable identities in which the rate of infragroups might be higher (e.g., unemployment; incarceration, e.g., Sani, Elena, Scrignaro, \& McCollum, 2010). In this context, oSIM might help researchers better understand particular social groups memberships that are predictive of problematic and dysfunctional psychological behavior (e.g., Dingle, Stark, Cruwys, \& Best, 2015).

As a final observation, oSIM's ease of use and scalability of delivery means it can be implemented in large-scale studies with a range of different populations. This is an important factor when it comes to ensuring that empirical questions can be investigated with a diverse range of samples. Furthermore, its online delivery allows researchers to target specialized groups that may be difficult to reach in person, or who may be more comfortable completing a study in private rather than in a research laboratory. Speaking to the contextual adaptability 
of the tool, the questions that are asked of participants while they construct their maps such as how positive or representative respondents feel — can also be adjusted to reflect the needs of the particular research question. The potential reach of the tool is therefore even greater than hinted in the scope of the present paper.

It is important to recognize that the current research did not fully exploit oSIM to explore issues that arise in more diverse samples. Although we endeavored to collect data from samples that faced different transitional moments in life, and were able to capture diversity in terms of employment and age, these samples were limited in their racial and ethnic diversity. This is not a trivial point, particularly when trying to understand questions of identity change and well-being, as ethnic and racial minority groups have been shown to face unique challenges on both fronts (Benet-Martínez \& Haritatos, 2005; Lu, Lindsey, Irsheid, \& Nebbitt, 2017). This naturally limits the conclusions we are able to draw when assessing issues of social identity and adjustment. We look forward to oSIM being used to tackle these core psychological questions in more diverse samples, and particularly to being able to target specific cultural groups whose identity content will allow researchers to better interrogate key oSIM constructs such as identity compatibility (e.g., among bicultural populations; BenetMartinez \& Haritatos, 2005).

\section{Conclusions}

This paper presented findings from four studies, each assessing psychometric properties of the oSIM tool. Results revealed that the tool is interesting and easy to use, reliable and valid, and able to predict relevant outcomes variables in a range of social contexts. Furthermore, we showed that oSIM can be used to create a higher order construct of highquality groups that predicts well-being and resilience over time. In short, online Social Identity Mapping is an engaging and theoretically informed methodology capable of distilling and cataloguing the elements that go into a happy and healthy life. 


\section{References}

Anan, R. M., \& Barnett, D. (1999). Perceived Social Support Mediates Between Prior Attachment and Subsequent Adjustment: A Study of Urban African American Children. Developmental Psychology, 35(5), 1210-1222. doi:10.1037/00121649.35.5.1210

Andresen, E. M., Malmgren, J. A., Carter, W. B., \& Patrick, D. L. (1994). Screening for depression in well older adults: Evaluation of a short form of the CES-D. American Journal of Preventive Medicine, 10(2), 77-84.

Barnes, J. A. (1954). Class and Committees in a Norwegian Island Parish. Human Relations, 7(1), 39-58. doi:10.1177/001872675400700102

Bates, D., Maechler, M., Bolker, B., \& Walker, S. (2015). Fitting linear mixed-effects models using lme4. Journal of Statistical Software, 67(1), 1-48. doi:10.18673/jss.v067.i01

Bean, J. P., \& Metzner, B. S. (1985). A Conceptual Model of Nontraditional Undergraduate Student Attrition. Review of Educational Research, 55(4), 485-540. doi:10.3102/00346543055004485

Beckwith, M., Best, D., Savic, M., Haslam, C., Bathish, R., Dingle, G., . . Lubman, D. I. (2018). Social Identity Mapping in Addiction Recovery (SIM-AR): extension and application of a visual method. Addiction Research \& Theory, 27(6), 1-10. doi:10.1080/16066359.2018.1544623

Belsky, J. (1984). determinants of parenting: a process model. determinants of parenting: a process model, 55(1), 83-96. doi:10.2307/1129836

Bentley, S. V., Greenaway, K. H., \& Haslam, S. A. (2017). Cognition in context: Social inclusion attenuates the psychological boundary between self and other. Journal of experimental social psychology, 73, 42-49. doi:10.1016/j.jesp.2017.06.008 
Bentley, S. V., Greenaway, K. H., Haslam, S. A., \& Haslam, C. (In preparation). GROUPS 4 EDUCATION: A social identity informed programme to increase social connectedness amongst university students. Unpublished manuscript.

Bentley, S. V., Peters, K., Haslam, S. A., \& Greenaway, K. H. (2019). Construction at Work: Multiple Identities Scaffold Professional Identity Development in Academia. Frontiers in Psychology, 10. doi:10.3389/fpsyg.2019.00628

Berkman, L. F., Glass, T., Brissette, I., \& Seeman, T. E. (2000). From social integration to health: Durkheim in the new millennium is the the paper is adapted from Berkman, L.F., \& Glass, T. Social integration, social networks, social support and health. In L. F. Berkman \& I. Kawachi, Social Epidemiology. New York: Oxford University Press and Brissette, I., Cohen S., Seeman, T. Measuring social integration and social networks. In S. Cohen, L. Underwood \& B. Gottlieb, Social Support Measurements and Intervention. New York: Oxford University Press. Social Science \& Medicine, 51(6), 843-857. doi:10.1016/S0277-9536(00)00065-4

Berkman, L. F., \& Syme, L. S. (2017). REPRINT: Social Networks, Host Resistance, and Mortality: A Nine-Year Follow-up Study of Alameda County Residents. American Journal of Epidemiology, 185(11), 1070-1088. doi:10.1093/aje/kwx103

Best, D., Beckwith, M., Haslam, C., Alexander Haslam, S., Jetten, J., Mawson, E., \& Lubman, D. I. (2016). Overcoming alcohol and other drug addiction as a process of social identity transition: the social identity model of recovery (SIMOR). Addiction Research \& Theory, 24(2), 111-123. doi:10.3109/16066359.2015.1075980

Bonanno, G. (2004). Loss, trauma, and human resilience - Have we underestimated the human capacity to thrive after extremely aversive events? Am. Psychol., 59(1), 20-28. doi:10.1037/0003-066X.59.1.20 
Bonanno, G. A., \& Diminich, E. D. (2013). Annual Research Review: Positive adjustment to adversity - trajectories of minimal-impact resilience and emergent resilience (Vol. 54, pp. 378-401).

Booth, C. L., Rubin, K. H., \& Rose-Krasnor, L. (1998). Perceptions of Emotional Support from Mother and Friend in Middle Childhood: Links with Social-Emotional Adaptation and Preschool Attachment Security. Child development, 69(2), 427-442. doi: $10.2307 / 1132176$

Brook, A. T., Garcia, J., \& Fleming, M. A. (2008). The Effects of Multiple Identities on Psychological Well-Being. Personality and Social Psychology Bulletin, 34(12), 15881600. doi:10.1177/0146167208324629

Brown, G., \& Rafaeli, E. (2007). Components of Self-Complexity as Buffers for Depressed Mood. J Cogn Psychother(4), 310-333. doi:10.1891/088983907782638761

Bugental, D. B., Ellerson, P. C., Lin, E. K., Rainey, B., Kokotovic, A., \& O'Hara, N. (2002). A Cognitive Approach to Child Abuse Prevention. Journal of Family Psychology, 16(3), 243-258. doi:10.1037/0893-3200.16.3.243

Cameron, J. E. (2004). A Three-Factor Model of Social Identity. Self and Identity, 3(3), 239262. doi:10.1080/13576500444000047

Carstensen, L. L. (2006). Influence of a Sense of Time on Human Development. Influence of a Sense of Time on Human Development, 312(5782), 1913-1915. doi: $10.1126 /$ science. 1127488

Chartrand, J. M. (1992). An Empirical Test of a Model of Nontraditional Student Adjustment. Journal of Counseling Psychology, 39(2), 193-202. doi:10.1037/00220167.39.2.193 
Cohen, J. S., Doyle, B. W., Turner, M. R., Alper, P. C., \& Skoner, P. D. (2003). Emotional Style and Susceptibility to the Common Cold. Psychosomatic Medicine, 65(4), 652657. doi:10.1097/01.PSY.0000077508.57784.DA

Cohen, S., Doyle, W. J., Skoner, D. P., Rabin, B. S., \& Gwaltney, J. M. (1997). Social Ties and Susceptibility to the Common Cold. JAMA, 277(24), 1940-1944. doi:10.1001/jama.1997.03540480040036

Cooper, H., \& Patall, E. A. (2009). The Relative Benefits of Meta-Analysis Conducted with Individual Participant Data versus Aggregated Data. Psychological methods, 14(2), 165-176. doi:10.1037/a0015565

Cruwys, T., Dingle, G. A., Haslam, C., Haslam, S. A., Jetten, J., \& Morton, T. A. (2013). Social group memberships protect against future depression, alleviate depression symptoms and prevent depression relapse. Social Science \& Medicine, 98, 179.

Cruwys, T., Haslam, S. A., Dingle, G. A., Haslam, C., \& Jetten, J. (2014). Depression and Social Identity: An Integrative Review. Personality and Social Psychology Review, 18(3), 215-238. doi:10.1177/1088868314523839

Cruwys, T., Steffens, N. K., Haslam, S. A., Haslam, C., Jetten, J., \& Dingle, G. A. (2016). Social Identity Mapping: A procedure for visual representation and assessment of subjective multiple group memberships. British Journal of Social Psychology, 55(4), 613-642. doi:10.1111/bjso.12155

Daempfle, P. A. (2003). An Analysis of the High Attrition Rates among First Year College Science, Math, and Engineering Majors. Journal of College Student Retention, 5(1), 37-52. doi:10.2190/DWQT-TYA4-T20W-RCWH

Dingle, G. A., Stark, C., Cruwys, T., \& Best, D. (2015). Breaking good: Breaking ties with social groups may be good for recovery from substance misuse. British Journal of Social Psychology, 54(2), 236-254. doi:10.1111/bjso.12081 
Dutton, J. E., Roberts, L. M., \& Bednar, J. (2010). Pathways for positive identity construction at work: four types of positive identity and the building of social resources.(Report). Academy of Management Review, 35(2), 265. doi:10.5465/AMR.2010.48463334

Eggins, R. A., O' Brien, A. T., Reynolds, K. J., Haslam, S. A., \& Crocker, A. S. (2008). Refocusing the Focus Group: AIRing as a Basis for Effective Workplace Planning. British Journal of Management, 19(3), 277-293. doi:10.1111/j.14678551.2007.00541.X

Ellemers, N., Kortekaas, P., \& Ouwerkerk, J. W. (1999). Self- categorisation, commitment to the group and group self- esteem as related but distinct aspects of social identity. European Journal of Social Psychology, 29(2- 3), 371-389. doi:10.1002/(SICI)10990992

Ellemers, N., Spears, R., \& Doosje, B. (2002). Self and social identity. Annual Review of Psychology, 53, 161.

Fonagy, P., Steele, H., \& Steele, M. (1991). Maternal Representations of Attachment during Pregnancy Predict the Organization of Infant- Mother Attachment at One Year of Age. Child development, 62(5), 891-905. doi:10.1111/j.1467-8624.1991.tb01578.x

Forster, P., \& Morris, M. (2012). Successful transition to retirement in Australia. Social Sciences Directory, 01(01), 4-12. doi:10.7563/SSD_01_01_01

Fratiglioni, L., Paillard-Borg, S., \& Winblad, B. (2004). An active and socially integrated lifestyle in late life might protect against dementia. Lancet Neurology, 3(6), 343-353. doi:10.1016/S1474-4422(04)00767-7

Galatzer-Levy, I., Burton, C., \& Bonanno, G. (2012). Coping flexibility, potentially traumatic life events, and resilience: a prospective study of college student adjustment. Journal of Social and Clinical Psychology, 31(6), 542-567. doi:10.1521/jscp.2012.31.6.542 
Greenaway, K. H., Cruwys, T., Haslam, S. A., \& Jetten, J. (2016). Social identities promote well- being because they satisfy global psychological needs. European Journal of Social Psychology, 46(3), 294-307. doi:10.1002/ejsp.2169

Greenaway, K. H., Haslam, S. A., Cruwys, T., Branscombe, N. R., Ysseldyk, R., \& Heldreth, C. (2015). From "We" to "Me": Group Identification Enhances Perceived Personal Control With Consequences for Health and Well-Being. Journal of personality and social psychology, 109(1), 53-74. doi:10.1037/pspi0000019

Greenaway, K. H., Wright, R. G., Willingham, J., Reynolds, K. J., \& Haslam, S. A. (2015). Shared Identity Is Key to Effective Communication. Personality and Social Psychology Bulletin, 41(2), 171-182. doi:10.1177/0146167214559709

Gresky, D., Eyck, L., Lord, C., \& McIntyre, R. (2005). Effects of Salient Multiple Identities on Women's Performance Under Mathematics Stereotype Threat. A Journal of Research, 53(9-10), 703-716. doi:10.1007/s11199-005-7735-2

Haslam, C., Cruwys, T., Bentley, S. V., Chang, M. X.-L., Haslam, S. A., Dingle, G. A., \& Jetten, J. (2019). Groups 4 Health reduces loneliness and social anxiety in adults with psychological distress: Findings from a randomized controlled trial. Journal of consulting and clinical psychology.

Haslam, C., Cruwys, T., Haslam, S. A., Dingle, G., \& Chang, M. X.-L. (2016). Groups 4 Health: Evidence that a social-identity intervention that builds and strengthens social group membership improves mental health. Journal of Affective Disorders, 194, 188195. doi:10.1016/j.jad.2016.01.010

Haslam, C., Holme, A., Haslam, S. A., Iyer, A., Jetten, J., \& Williams, W. H. (2008). Maintaining group memberships: Social identity continuity predicts well-being after stroke. Neuropsychological Rehabilitation, 18(5-6), 671-691. doi:10.1080/09602010701643449 
Haslam, C., Jetten, J., Cruwys, T., Dingle, G., \& Haslam, A. (2018a). The New Psychology of Health: Unlocking the Social Cure: Florence: Routledge.

Haslam, C., Jetten, J., Cruwys, T., Dingle, G., \& Haslam, S. A. (2018b). The New Psychology of Health : Unlocking the Social Cure: Florence: Routledge.

Haslam, C., Morton, T. A., Haslam, S. A., Varnes, L., Graham, R., \& Gamaz, L. (2012). "When the age is in, the wit is out": age-related self-categorization and deficit expectations reduce performance on clinical tests used in dementia assessment. Psychology and aging, 27(3), 778.

Haslam, C., Steffens, N., Cruwys, T., Lam, B. C. P., Pachana, N. A., \& Yang, J. (2018). The importance of social groups for retirement adjustment: Evidence, application, and policy implications of the Social Identity Model of Identity Change. Social Issues and Policy Review, In press.

Haslam, C., Steffens, N. K., Branscombe, N. R., Haslam, S. A., Cruwys, T., Lam, B. C. P., . . . Yang, J. (2019). The Importance of Social Groups for Retirement Adjustment: Evidence, Application, and Policy Implications of the Social Identity Model of Identity Change. Social Issues and Policy Review, 13(1), 93. doi:10.1111/sipr.12049

Haslam, S. A., Eggins, R. A., \& Reynolds, K. J. (2003). The ASPIRe model: Actualizing Social and Personal Identity Resources to enhance organizational outcomes. Journal of Occupational and Organizational Psychology, 76(1), 83-113. doi:10.1348/096317903321208907

Haslam, S. A., \& Ellemers, N. (2011). Identity Processes in Organizations (pp. 715-744). New York, NY: Springer New York.

Haslam, S. A., Reicher, S., \& Platow, M. (2011). The new psychology of leadership : identity, influence, and power: New York : Psychology Press. 
Haslam, S. A., Reicher, S. D., \& Levine, M. (2012). When other people are heaven, when other people are hell: How social identity determines the nature and impact of social support The Social Cure: Identity, Health and Well-Being (pp. 157-174). New York: Psychology Press.

Haslam, S. A., Steffens, N. K., Peters, K., Boyce, R. A., Mallett, C. J., \& Fransen, K. (2017). A Social Identity Approach to Leadership Development. Journal of Personnel Psychology, 16(3), 113-124. doi:10.1027/1866-5888/a000176

He, H., Brown, A. D., Peters, K., Haslam, S. A., Ryan, M. K., \& Fonseca, M. (2013). Working With Subgroup Identities to Build Organizational Identification and Support for Organizational Strategy. Group \&amp; Organization Management, 38(1), 128144. doi: $10.1177 / 1059601112472368$

Hirsch, B. J. (1979). Psychological dimensions of social networks: A multimethod analysis. American Journal of Community Psychology, 7(3), 263-277. doi:10.1007/BF00890691

Hirsh, J. B., \& Kang, S. K. (2016). Mechanisms of Identity Conflict. Personality and Social Psychology Review, 20(3), 223-244. doi:10.1177/1088868315589475

Hogg, M., \& Hardie, E. (1992). Prototypicality, conformity and depersonalized attraction - a self-categorization analysis of group cohesiveness. British Journal of Social Psychology, 31(1), 41-56. doi:10.1111/j.2044-8309.1992.tb00954.x

Hogg, M. A., Van Knippenberg, D., \& Rast, D. E. (2012). The social identity theory of leadership: Theoretical origins, research findings, and conceptual developments. European Review of Social Psychology, 23(1), 258-304.

doi:10.1080/10463283.2012.741134 
Holt-Lunstad, J., Smith, T. B., \& Layton, J. B. (2010). Social Relationships and Mortality Risk: A Meta-analytic Review (Social Relationships and Mortality). PLoS Medicine, 7(7), e1000316. doi:10.1371/journal.pmed.1000316

House, J., Landis, K., \& Umberson, D. (1988). Social Relationships and Health. Science, 241(4865), 540. doi:10.1126/science.3399889

House, J., Robbins, C., \& Metzner, H. (1982). The Association of Social Relationships and Activities with Mortality: Prospective Evidence from the Tecumseh Community Health Study. American Journal of Epidemiology, 116(1), 123. doi:10.1093/oxfordjournals.aje.a113387

Iyer, A., Jetten, J., Tsivrikos, D., Postmes, T., \& Haslam, S. A. (2009). The more (and the more compatible) the merrier: Multiple group memberships and identity compatibility as predictors of adjustment after life transitions. British Journal of Social Psychology, 48(4), 707-733. doi:10.1348/014466608X397628

Jetten, J., Branscombe, N., Haslam, S., Haslam, C., Cruwys, T., Jones, J., . . Zhang, A. (2015). Having a Lot of a Good Thing: Multiple Important Group Memberships as a Source of Self-Esteem. PLOS ONE, 10(5), e0124609. doi:10.1371/journal.pone.0124609

Jetten, J., Haslam, C., \& Haslam, S. A. (2012). The social cure: Identity, health and wellbeing. Hove England; New York: Psychology Press.

Jetten, J., Haslam, C., Pugliese, C., Tonks, J., \& Haslam, S. A. (2010). Declining autobiographical memory and the loss of identity: Effects on well-being. Journal of Clinical and Experimental Neuropsychology, 32(4), 408-416. doi:10.1080/13803390903140603

Jetten, J., Haslam, S. A., Cruwys, T., Greenaway, K. H., Haslam, C., \& Steffens, N. K. (2017). Advancing the social identity approach to health and well- being: Progressing 
the social cure research agenda. European Journal of Social Psychology, 47(7), 789802. doi:10.1002/ejsp.2333

Jetten, J., Haslam, S. A., Iyer, A., \& Haslam, C. (2009a). Consequences of Giving or Receiving Help in the Context of Groups. In S. Sturmer \& M. Snyder (Eds.), The Psychology of Prosocial Behavior (pp. 139-156): Oxford, UK: Wiley- Blackwell. Jetten, J., Haslam, S. A., Iyer, A., \& Haslam, C. (2009b). Turning to others in times of change: Shared identity and coping with stress. In S. Sturmer \& M. Snyder (Eds.), The Psychology of Prosocial Behviour (pp. 139-156): Oxford, UK: WileyBlackwell.

Jetten, J., \& Pachana, N. A. (2012). Not wanting to grow old: A Social Identity Model of Identity Change (SIMIC) analysis of driving cessation among older adults The Social Cure: Identity, Health and Well-Being (pp. 97-114). Hove \& New York,. Psychology Press.

Jones, J. M., \& Jetten, J. (2011). Recovering From Strain and Enduring Pain: Multiple Group Memberships Promote Resilience in the Face of Physical Challenges. Social Psychological and Personality Science, 2(3), 239-244. doi:10.1177/1948550610386806

Judd, C. M., Westfall, J., \& Kenny, D. A. (2012). Treating Stimuli as a Random Factor in Social Psychology: A New and Comprehensive Solution to a Pervasive but Largely Ignored Problem. Journal of personality and social psychology, 103(1), 54-69. doi:10.1037/a0028347

Kane, A. (2010). Unlocking Knowledge Transfer Potential: Knowledge Demonstrability and Superordinate Social Identity. Organization Science, 21(3), 643-660. doi:10.1287/orsc. 1090.0469 
Kane, A. A., Argote, L., \& Levine, J. M. (2005). Knowledge transfer between groups via personnel rotation: Effects of social identity and knowledge quality. Organizational Behavior and Human Decision Processes, 96(1), 56-71. doi:10.1016/j.obhdp.2004.09.002

Kearns, M., Muldoon, O. T., Msetfi, R. M., \& Surgenor, P. W. G. (2018). Identification Reduces Stigma of Mental Ill- Health: A Community- Based Study. American Journal of Community Psychology, 61(1-2), 229-239. doi:10.1002/ajcp.12220

Khan, S. S., Hopkins, N., Tewari, S., Srinivasan, N., Reicher, S. D., \& Ozakinci, G. (2014). Efficacy and well- being in rural north India: The role of social identification with a large- scale community identity. European Journal of Social Psychology, 44(7), 787798. doi:10.1002/ejsp.2060

Krause, K. L., \& Coates, H. (2008). Students' engagement in first- year university. Assessment \& Evaluation in Higher Education, 33(5), 493-505. doi:10.1080/02602930701698892

Kuznetsova, A., Brockhoff, P., \& Christensen, R. (2017). lmerTest Package: Tests in Linear Mixed Effects Models. J. Stat. Softw., 82(13), 1-26. doi:10.18637/jss.v082.i13

Lam, B. C. P., Haslam, C., Haslam, S. A., Steffens, N. K., Cruwys, T., Jetten, J., \& Yang, J. (2018). Multiple social groups support adjustment to retirement across cultures. Social Science \& Medicine, 208, 200-208. doi:10.1016/j.socscimed.2018.05.049

Leach, C. W., Ellemers, N., \& Barreto, M. (2007). Group Virtue: The Importance of Morality (vs. Competence and Sociability) in the Positive Evaluation of In-Groups. Journal of personality and social psychology, 93(2), 234-249. doi:10.1037/0022-3514.93.2.234

Leach, C. W., Van Zomeren, M., Zebel, S., Vliek, M. L. W., Pennekamp, S. F., Doosje, B., . . . Spears, R. (2008). Group-Level Self-Definition and Self-Investment: A Hierarchical 
(Multicomponent) Model of In-Group Identification. Journal of personality and social psychology, 95(1), 144-165. doi:10.1037/0022-3514.95.1.144

Levine, M., Prosser, A., Evans, D., \& Reicher, S. (2005). Identity and Emergency Intervention: How Social Group Membership and Inclusiveness of Group Boundaries Shape Helping Behavior. Personality and Social Psychology Bulletin, 31(4), 443-453. doi:10.1177/0146167204271651

Libbey, H. P. (2004). Measuring Student Relationships to School: Attachment, Bonding, Connectedness, and Engagement. Journal of School Health, 74(7), 274-283. doi:10.1111/j.1746-1561.2004.tb08284.x

Linville, P. W. (1987). Self-Complexity as a Cognitive Buffer Against Stress-Related Illness and Depression. Journal of personality and social psychology, 52(4), 663-676. doi:10.1037/0022-3514.52.4.663

Liu, J. H., Wilson, M. S., McClure, J., \& Higgins, T. R. (1999). Social identity and the perception of history: cultural representations of Aotearoa/New Zealand. European Journal of Social Psychology, 29(8), 1021-1047. doi:10.1002/(SICI)10990992(199912)29:8\&lt;1021::AID-EJSP975\&gt;3.0.CO;2-4

Lovibond, S. H., \& Lovibond, P. F. (1995). Manual for the depression anxiety stress scales. In A. Psychology Foundation of (Ed.), (2nd ed.. ed.): Sydney, N.S.W. : Psychology Foundation of Australia.

Murray, L., Fiori- Cowley, A., Hooper, R., \& Cooper, P. (1996). The Impact of Postnatal Depression and Associated Adversity on Early Mother- Infant Interactions and Later Infant Outcome. Child development, 67(5), 2512-2526. doi:10.1111/j.14678624.1996.tb01871.x 
Paluck, E. L., Shepherd, H., \& Aronow, P., M. . (2016). Changing climates of conflict: A social network experiment in 56 schools. Proceedings of the National Academy of Sciences, 113(3), 566. doi:10.1073/pnas.1514483113

Pianta, R. C., \& Steinberg, M. (1992). Teacher- child relationships and the process of adjusting to school. New Directions for Child and Adolescent Development, 1992(57), 61-80. doi:10.1002/cd.23219925706

Polanin, J. R., Hennessy, E. A., \& Tanner-Smith, E. E. (2017). A Review of Meta-Analysis Packages in R. Journal of Educational and Behavioral Statistics, 42(2), 206-242. doi:10.3102/1076998616674315

Postmes, T., Haslam, S. A., \& Jans, L. (2013). A single-item measure of social identification: Reliability, validity, and utility. British Journal of Social Psychology, 52(4), 597. doi:10.1111/bjso.12006

Putnam, R. (2001). Bowling alone: the collapse and revival of American community. In R. Putnam (Ed.), (Vol. 38, pp. 86-89).

Putnam, R. D., Leonardi, R., \& Nanetti, R. Y. (1993). Making democracy work : civic traditions in modern Italy: Princeton, N.J. : Princeton University Press.

Rammstedt, B., \& John, O. P. (2007). Measuring personality in one minute or less: A 10-item short version of the Big Five Inventory in English and German. Journal of Research in Personality, 41(1), 203-212. doi:10.1016/j.jrp.2006.02.001

Reynolds, K. J., Eggins, R. A., \& Haslam, S. A. (2010). Uncovering diverse identities in organisations: AIRing versus auditing approaches to diversity management. Asia Pacific Journal of Human Resources, 48(1), 45-57. doi:10.1177/1038411109355376

Reynolds, W. M. (1982). Development of reliable and valid short forms of the MarloweCrowne social desirability scale. Journal of Clinical Psychology, 38(1), 119-125. doi:10.1002/1097-4679 
Rosenthal, L., London, B., Levy, S., \& Lobel, M. (2011). The Roles of Perceived Identity Compatibility and Social Support for Women in a Single-Sex STEM Program at a Co-educational University. A Journal of Research, 65(9), 725-736. doi:10.1007/s11199-011-9945-0

Sani, F. (2012). The Social Cure: Identity, Health and Well-Being. In J. Jetten, C. Haslam, \& S. A. Haslam (Eds.), The Social Cure: Identity, Health and Well-Being (pp. 21-38): Hove

New York : Psychology Press.

Sani, F., Elena, M. M., Scrignaro, M., \& McCollum, R. (2010). In- group identification mediates the effects of subjective in- group status on mental health. British Journal of Social Psychology, 49(4), 883-893. doi:10.1348/014466610X517414

Sani, F., Madhok, V., Norbury, M., Dugard, P., \& Wakefield, J. R. H. (2015). Greater number of group identifications is associated with healthier behaviour: Evidence from a Scottish community sample. British Journal of Health Psychology, 20(3), 466-481. doi:10.1111/bjhp.12119

Schonbrodt, F. D., \& Perugini, M. (2013). At what sample size do correlations stabilize? Journal of Research in Personality, 47(5), 609. doi:10.1016/j.jrp.2013.05.009

Schwarzer, R., \& Leppin, A. (1991). Social Support and Health: A Theoretical and Empirical Overview. Journal of Social and Personal Relationships, 8(1), 99-127. doi:10.1177/0265407591081005

Seymour-Smith, M., Cruwys, T., Haslam, S. A., \& Brodribb, W. (2017). Loss of group memberships predicts depression in postpartum mothers. The International Journal for Research in Social and Genetic Epidemiology and Mental Health Services, 52(2), 201-210. doi:10.1007/s00127-016-1315-3 
Showers, C. (1992). Compartmentalization of Positive and Negative Self-Knowledge: Keeping Bad Apples Out of the Bunch. Journal of personality and social psychology, 62(6), 1036-1049. doi:10.1037/0022-3514.62.6.1036

Smyth, L., Reynolds, K. J., Grace, D. M., Platow, M. J., \& Mavor, K. I. (2015). Discipline social identification, study norms and learning approach in university students. Educational Psychology, 35(1), 53-72. doi:10.1080/01443410.2013.822962

Spears, R., Jetten, J., \& Scheepers, D. (2002). Distinctiveness and the definition of collective self: A tripartite model: American Psychological Association.

Spillius, E. B. (1957). Family and social network : roles, norms and external relationships in ordinary urban families: London : Tavistock Publications.

Spitzer, R. L., Kroenke, K., \& Williams, J. B. W. (1999). Validation and Utility of a Selfreport Version of PRIME-MD: The PHQ Primary Care Study. JAMA, 282(18), 17371744. doi:10.1001/jama.282.18.1737

Steffens, N. K., Cruwys, T., Haslam, C., Jetten, J., \& Haslam, S. A. (2016). Social group memberships in retirement are associated with reduced risk of premature death: evidence from a longitudinal cohort study. BMJ Open, 6(2). doi:10.1136/bmjopen2015-010164

Steffens, N. K., Gocłowska, M. A., Cruwys, T., \& Galinsky, A. D. (2016). How Multiple Social Identities Are Related to Creativity. Personality and Social Psychology Bulletin, 42(2), 188-203. doi:10.1177/0146167215619875

Stephens, N. M., Hamedani, M. G., \& Destin, M. (2014). Closing the social-class achievement gap: a difference-education intervention improves first-generation students' academic performance and all students' college transition. Psychological Science, 25(4), 943. doi:10.1177/0956797613518349 
Tajfel, H. (1972). Social categorization. In S. Moscovici (Ed.), Introduction à la psychologie sociale (Vol. 1, pp. 272-302). Paris, France: Larousse.

Tajfel, H., \& Turner, J. C. (1979). An integrative theory of intergroup conflict. In W. G. Austin \& S. Worchel (Eds.), The Social Psychology of Intergroup Relations (pp. 3347). Monterey, Calif: Brooks/Cole Pub. Co.

Thoits, P. (1995). Stress, coping, and social support processes: Where are we? What next? Journal of Health and Social Behavior, 53-53.

Turner, J. C., Hogg, M. A., Oakes, P. J., Reicher, S. D., \& Wetherell, M. S. (1987a). Rediscovering the social group : a self-categorization theory: New York : Basil Blackwell.

Turner, J. C., Hogg, M. A., Oakes, P. J., Reicher, S. D., \& Wetherell, M. S. (1987b). Rediscovering the social group: a self-categorization theory. Oxford ; New York: Basil Blackwell.

van Breen, J. A., Spears, R., Kuppens, T., \& de Lemus, S. (2017). A multiple identity approach to gender: Identification with women, identification with feminists, and their interaction. Frontiers in Psychology, 8, <xocs:firstpage xmlns:xocs="'"/>. doi:10.3389/fpsyg.2017.01019

Van de Velde, S., Levecque, K., \& Bracke, P. (2009). Measurement equivalence of the CESD 8 in the general population in Belgium: A gender perspective. Archives of Public Health, 67(1), 15-29. doi:10.1186/0778-7367-67-1-15

Viechtbauer, W. (2010). Conducting meta-analyses in R with the metafor package. Journal of Statistical Software.

Vogel, F. R., \& Human-Vogel, S. (2016). Academic Commitment and Self-Efficacy as Predictors of Academic Achievement in Additional Materials Science. Higher 
Education Research and Development, 35(6), 1298-1310.

doi:10.1080/07294360.2016.1144574

Vogt, T. M., Mullooly, J. P., Ernst, D., Pope, C. R., \& Hollis, J. F. (1992). Social networks as predictors of ischemic heart disease, cancer, stroke and hypertension: Incidence, survival and mortality. Journal of Clinical Epidemiology, 45(6), 659-666. doi:10.1016/0895-4356(92)90138-D

Waldzus, S., Mummendey, A., \& Wenzel, M. (2005). When "different" means "worse": Ingroup prototypicality in changing intergroup contexts. Journal of experimental social psychology, 41(1), 76-83. doi:10.1016/j.jesp.2004.05.006

Walton, G. M., \& Cohen, G. L. (2011). A brief social-belonging intervention improves academic and health outcomes of minority students.(REPORTS)(Author abstract)(Report). Science, 331(6023), 1447. doi:10.1126/science.1198364

Walton, G. M., Logel, C., Peach, J. M., Spencer, S. J., \& Zanna, M. P. (2015). Two Brief Interventions to Mitigate a "Chilly Climate” Transform Women's Experience, Relationships, and Achievement in Engineering. Journal of educational psychology, 107(2), 468-485. doi:10.1037/a0037461

Wells, Y., de Vaus, D., Kendig, H., Quine, S., \& Peteralia, W. (2006). Healthy retirement project: Technical report. Retrieved from http://arrow.latrobe.edu.au:8080/vital/access/manager/Repository/latrobe:22972

Yeager, D. S., Romero, C., Paunesku, D., Hulleman, C. S., Schneider, B., Hinojosa, C., . . Dweck, C. S. (2016). Using Design Thinking to Improve Psychological Interventions: The Case of the Growth Mindset during the Transition to High School. Journal of educational psychology, 108(3), 374-391. doi:10.1037/edu0000098

Yeager, D. S., Walton, G. M., Brady, S. T., Akcinar, E. N., Paunesku, D., Keane, L., . . Dweck, C. S. (2016). Teaching a lay theory before college narrows achievement gaps 
at scale.(PSYCHOLOGICAL AND COGNITIVE SCIENCES)(Report). 113(24), E3341. doi:10.1073/pnas.1524360113 


\section{Appendix 1}

\section{oSIM screen presentation}
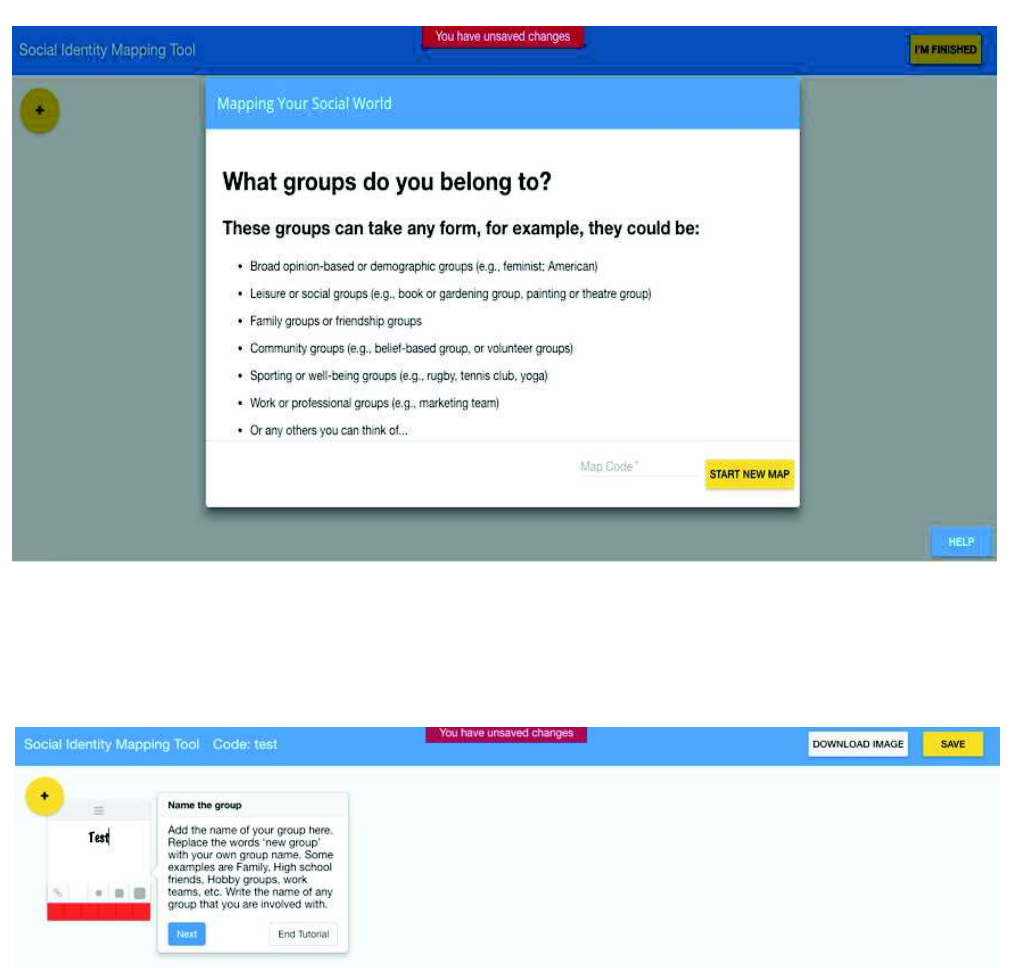

First, participants are presented with an introductory pop-up which begins the mapping process by getting participants to start thinking about the groups in their lives.

Next, the tutorial begins with a pop-up which instructs participants on how to create their first group.

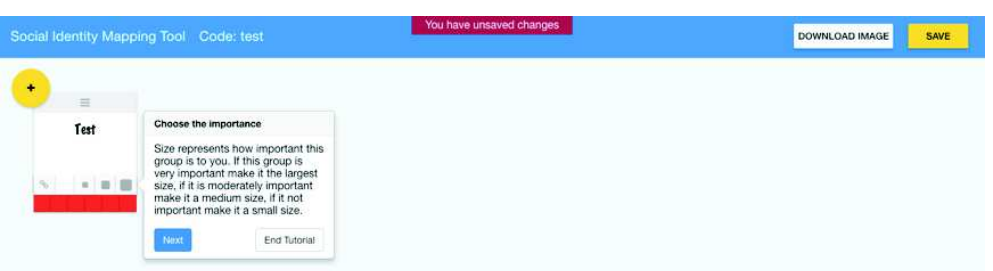

The next tutorial pop-up explains how to choose the size of e-note according to the group's importance. 


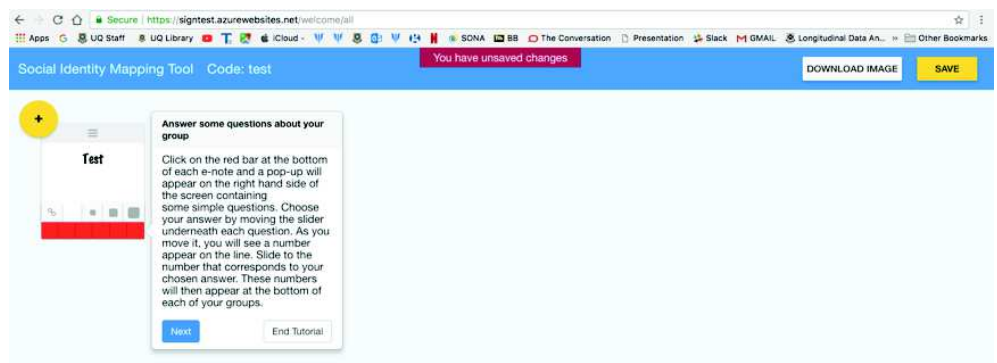

Next, participants are instructed on how to answer questions about each group.

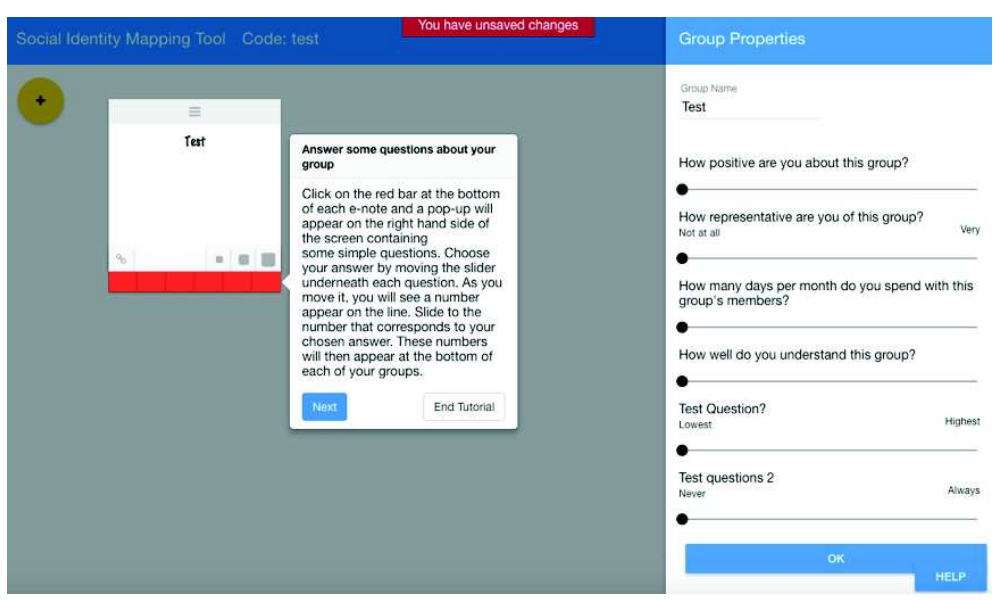

These questions appear as a slide-in pop-up when the red bar on each e-note is clicked.

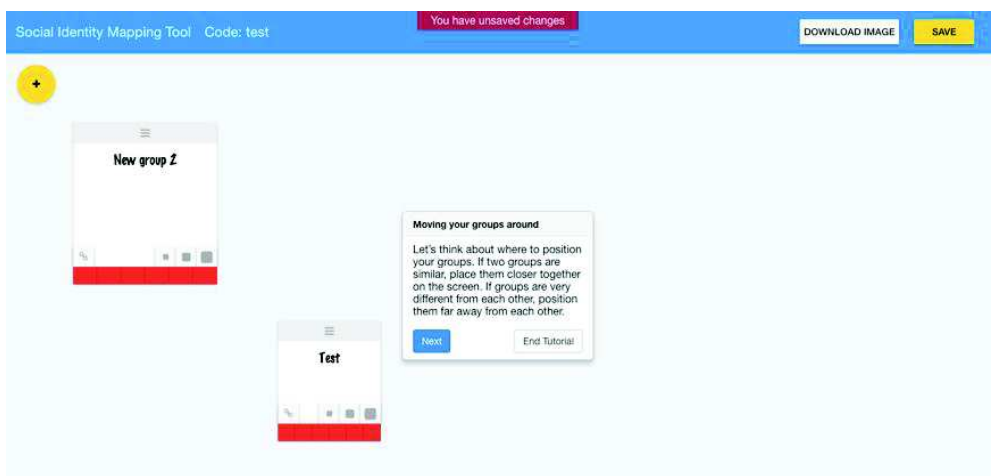

Participants are then given instructions on how to create more groups, and how to move the groups around. They are told to position similar groups close together and dissimilar groups far apart. 


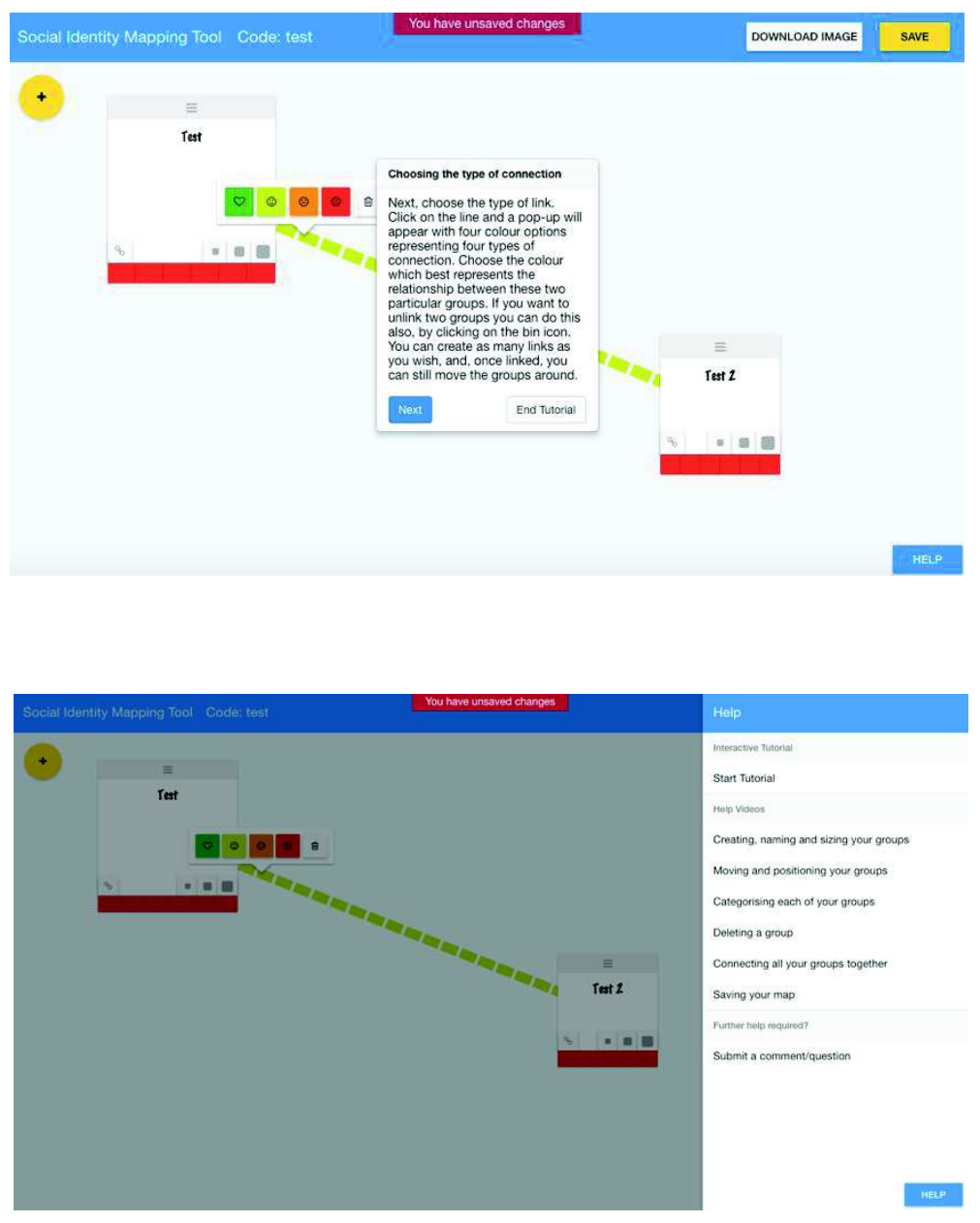

Participants are then asked to think about the compatibility of their groups. The tutorial explains how to link each group together, and how to determine the quality of the link by using the coding palette.

Finally, participants are shown where to access the Help videos, should they require further assistance when building their map.

This is the end of the tutorial, and, after this, participants are given as much time as they need to create their own map. 


\section{Appendix 2}

\section{oSIM introductory statement and tutorial text}

\section{What groups did you belong to?}

These groups can take any form, for example, they could be:

- Broad opinion-based or demographic groups (e.g., feminist; American)

- Leisure or social groups (e.g., book or gardening group, painting or theatre group)

- Family groups or friendship groups

- Community groups (e.g., belief-based group, or volunteer groups)

- Sporting or well-being groups (e.g., rugby, tennis club, yoga)

- Work or professional groups (e.g., marketing team)

- Or any others you can think of...

Add as many groups as you like in order to create the best representation of yourself and your social world.

The tutorial will now start: Please follow the instructions in each pop-up and start creating your map as you go.

Add a group: First things first. Let's add a new group to our map. Click on the yellow 'plus' button here.

Name the group: Add the name of your group here. Replace the words 'new group' with your own group name. Some examples are Family, high school friends, hobby groups, work teams etc. Write the name of any group that you are involved with.

Choose the importance: Size represents how important this group is to you. If this group is very important make it the largest size, if it is moderately importance make it a medium size, if it is not important make it a small size.

Move the group around: OK, now try to move the group around using he handle in the grey bar at the top of the group.

Answer some questions about your group. Click on the red bar at the bottom of each e-note and a pop-up will appear on the right hand side of the screen containing some simple questions. Choose your answer by moving the slider underneath each question. As you move it, you will see a number appear on the line. Slide to the number that corresponds to your chosen answer. These numbers will then appear at the bottom of each of your groups.

Add a second group: Now, let's add another group to the map.

Moving your groups around: Let's think about where to position your groups. If two groups are similar, place them closer together on the screen. If groups are very different from each other, position them far away from each other.

Connecting your groups together: It's good to think about how your groups fit together. Are two particular groups compatible? Or do they clash? You can use linking lines to represent how your groups fit together. To create a link from one group to another, click and drag the chain icon to any other group. 
Choose the type of presentation: Next, choose the type of link. Click on the line and a popup will appear with four colour options representing four types of connection. Choose the colour which best represents the relationship between these two particular groups. If you want to unlink two groups you can do this also, by clicking on the bin icon. You can create as many links as you wish, and, once linked, you can still move the groups around.

No limits: You can add in as many groups as you need to best represent yourself and your social world.

Don't forget to save: When you have created all your groups, positioned them, linked them, responded to the questions about them, and you are happy that you have created an accurate visual representation of all your groups, then you need to save the map. To do this, click the save button in the top right-hand side of the screen. 


\section{Appendix 3}

Table A1. Means, standard deviations (in parentheses) and correlations between oSIM variables on past and present maps and outcome variables (Study 2).

\begin{tabular}{|c|c|c|c|c|c|c|c|c|c|c|c|c|c|c|c|c|}
\hline & $M(S D)$ & 2 & 3 & 4 & 5 & 6 & 7 & 8 & 9 & 10 & 11 & 12 & 13 & 14 & 15 & 16 \\
\hline $\begin{array}{l}\text { 1. T1 oSIM: Total } \\
\text { number of groups }\end{array}$ & $6.75(1.67)$ & $.61^{* * *}$ & $.32^{* * *}$ & $.32^{* * *}$ & -.11 & .14 & -.06 & .08 & $.50^{* * *}$ & $.32^{* * *}$ & $.26^{* * *}$ & $.26^{* * *}$ & .08 & .10 & -.03 & $.17^{*}$ \\
\hline $\begin{array}{l}\text { 2. T1 oSIM: Number of } \\
\text { positive groups }\end{array}$ & $4.60(2.01)$ & & $.62^{* * *}$ & $.37^{* * *}$ & .04 & $.28^{* * *}$ & $-.21^{* *}$ & $.16^{*}$ & $.29^{* * *}$ & $.51^{* * *}$ & $.43^{* * *}$ & .15 & .07 & $.24^{* * *}$ & $-.17^{*}$ & $.20^{*}$ \\
\hline $\begin{array}{l}\text { 3. T1 oSIM: Number of } \\
\text { representative groups }\end{array}$ & $3.36(1.76)$ & & & $.32^{* * *}$ & .11 & $.20^{* *}$ & $-.22^{* *}$ & $.19^{*}$ & $.18^{*}$ & $.38^{* * *}$ & $.53^{* * *}$ & .08 & .13 & $.17^{* *}$ & $-.14^{*}$ & $.13^{*}$ \\
\hline $\begin{array}{l}\text { 4. T1 oSIM: Number of } \\
\text { high-contact groups }\end{array}$ & $2.36(1.40)$ & & & & -.04 & .06 & -.08 & .06 & $.27^{* * *}$ & $.35^{* * *}$ & $.37^{* * *}$ & $.59^{* * *}$ & .06 & .02 & -.02 & $.16^{*}$ \\
\hline $\begin{array}{l}\text { 5. T1 oSIM: Prop. } \\
\text { compatible links }\end{array}$ & $0.75(0.24)$ & & & & & -.03 & .01 & -.01 & -.07 & -.04 & .03 & $<.01$ & $.33^{* * *}$ & .05 & .01 & -.10 \\
\hline 6. T1 Life Satisfaction & $4.54(1.20)$ & & & & & $\alpha=.85$ & $-.55^{* * *}$ & $.24^{* * *}$ & .12 & $.21^{* *}$ & $.16^{*}$ & .07 & .05 & $.73^{* * *}$ & $-.32^{* * *}$ & $.23^{* * *}$ \\
\hline 7. T1 Depression & $11.37(3.52)$ & & & & & & $\alpha=.89$ & $-.28^{* * *}$ & -.02 & $-.16^{*}$ & -.13 & .04 & -.10 & $-.54^{* * *}$ & $.66^{* * *}$ & $-.32^{* * *}$ \\
\hline 8. T1 Study intentions & $5.88(0.70)$ & & & & & & & $\alpha=.73$ & -.04 & $.21^{* *}$ & $.17^{*}$ & -.06 & $-.17^{*}$ & $.15^{*}$ & $-.17^{*}$ & $.63^{* * *}$ \\
\hline $\begin{array}{l}\text { 9. T2 oSIM: Total } \\
\text { number of groups }\end{array}$ & $7.16(2.07)$ & & & & & & & & & $.65^{* * *}$ & $.51^{* * *}$ & $.31^{* * *}$ & .10 & $.18^{* *}$ & .04 & $.16^{*}$ \\
\hline $\begin{array}{l}\text { 10. T2 oSIM: Number of } \\
\text { positive groups }\end{array}$ & $4.84(2.21)$ & & & & & & & & & & $.77^{* * *}$ & $.30^{* * *}$ & .12 & $.29^{* * *}$ & -.10 & $.32^{* * *}$ \\
\hline $\begin{array}{l}\text { 11. T2 oSIM: Number of } \\
\text { representative groups }\end{array}$ & $3.71(2.21)$ & & & & & & & & & & & $.33^{* * *}$ & $.23^{* *}$ & $.23^{* *}$ & -.08 & $.26^{* * *}$ \\
\hline $\begin{array}{l}\text { 12. T2 oSIM: Number of } \\
\text { high-contact groups }\end{array}$ & $2.37(1.39)$ & & & & & & & & & & & & .13 & .07 & .05 & .11 \\
\hline $\begin{array}{l}\text { 13. T2 oSIM: Prop. } \\
\text { compatible links }\end{array}$ & $0.82(0.22)$ & & & & & & & & & & & & & $.18^{*}$ & $-.23^{* *}$ & -.04 \\
\hline 14. T2 Life satisfaction & $4.74(1.26)$ & & & & & & & & & & & & & $\alpha=.88$ & $-.51^{* * *}$ & $.34^{* * *}$ \\
\hline 15. T2 Depression & $11.34(3.40)$ & & & & & & & & & & & & & & $\alpha=.92$ & $-.29^{* * *}$ \\
\hline 16. T2 Study intentions & $5.83(0.78)$ & & & & & & & & & & & & & & & $\alpha=.75$ \\
\hline
\end{tabular}


Table A2. Means, standard deviations (in parentheses) and correlations between oSIM variables on past and present maps and outcome variables (Study 3).

\begin{tabular}{|c|c|c|c|c|c|c|c|c|c|c|c|c|c|c|c|}
\hline & $M(S D)$ & 2 & 3 & 4 & 5 & 6 & 7 & 8 & 9 & 10 & 11 & 12 & 13 & 14 & 15 \\
\hline $\begin{array}{l}\text { 1. Past oSIM: Total number } \\
\text { of groups }\end{array}$ & $3.41(1.54)$ & $.78^{* * * *}$ & $.53^{* * *}$ & $.50^{* * * *}$ & $.53^{* * *}$ & .05 & $.63^{* * *}$ & $.46^{* * *}$ & $.21^{* *}$ & $.29^{* * * *}$ & $.29^{* * *}$ & -.02 & -.06 & -.02 & .04 \\
\hline $\begin{array}{l}\text { 2. Past oSIM: Number of } \\
\text { positive groups }\end{array}$ & $2.61(1.33)$ & & $.69^{* * *}$ & $.62^{* * * *}$ & $.47^{* * *}$ & .14 & $.57^{* * *}$ & $.54^{* * *}$ & $.34^{* * *}$ & $.33^{* * *}$ & $.31^{* * *}$ & .05 & -.01 & $-.15^{*}$ & .06 \\
\hline $\begin{array}{l}\text { 3. Past oSIM: Number of } \\
\text { representative groups }\end{array}$ & $2.19(1.23)$ & & & $.62^{* * *}$ & $.40^{* * *}$ & $.19^{*}$ & $.49^{* * *}$ & $.40^{* * *}$ & $.46^{* * *}$ & $.34^{* * *}$ & $.29^{* * *}$ & $<.01$ & .07 & $-.19^{*}$ & .12 \\
\hline $\begin{array}{l}\text { 4. Past oSIM: Number of } \\
\text { supportive groups }\end{array}$ & $2.10(1.16)$ & & & & $.50^{* * *}$ & $.23^{* *}$ & $.44^{* * *}$ & $.39^{* * *}$ & $.28^{* * * *}$ & $.47^{* * *}$ & $.27^{* * *}$ & .06 & .09 & -.11 & .04 \\
\hline $\begin{array}{l}\text { 5. Past oSIM: Number of } \\
\text { high-contact groups }\end{array}$ & $1.69(1.25)$ & & & & & .11 & $.36^{* * *}$ & $.28^{* * *}$ & $.21^{* *}$ & $.24^{* *}$ & $.60^{* * *}$ & .03 & -.08 & -.04 & -.01 \\
\hline $\begin{array}{l}\text { 6. Past oSIM: prop. } \\
\text { compatible links }\end{array}$ & $0.83(0.32)$ & & & & & & .01 & .08 & .06 & $.15^{*}$ & .01 & $.35^{* * *}$ & $.15^{*}$ & $-.25^{* * *}$ & $.24^{* * *}$ \\
\hline $\begin{array}{l}\text { 7. Present oSIM: Total } \\
\text { number of groups }\end{array}$ & $3.51(1.59)$ & & & & & & & $.81^{* * *}$ & $.59^{* * *}$ & $.66^{* * *}$ & $.48^{* * *}$ & .07 & -.07 & -.04 & -.04 \\
\hline $\begin{array}{l}\text { 8. Present oSIM: Number of } \\
\text { positive groups }\end{array}$ & $2.83(1.60)$ & & & & & & & & $.71^{* * *}$ & $.79^{* * * *}$ & $.47^{* * *}$ & $.23^{* * *}$ & .06 & $-.21^{* *}$ & -.10 \\
\hline $\begin{array}{l}\text { 9. Present oSIM: Number of } \\
\text { representative groups }\end{array}$ & $2.20(1.41)$ & & & & & & & & & $.63^{* * *}$ & $.46^{* * *}$ & $.16^{*}$ & .05 & $-.19^{*}$ & .10 \\
\hline $\begin{array}{l}\text { 10. Present oSIM: Number } \\
\text { of supportive groups }\end{array}$ & $2.18(1.55)$ & & & & & & & & & & $.44^{* * *}$ & $.26^{* * *}$ & .09 & -.13 & .05 \\
\hline $\begin{array}{l}\text { 11. Present oSIM: Number } \\
\text { of high-contact groups }\end{array}$ & $1.62(1.27)$ & & & & & & & & & & & .10 & -.08 & .02 & -.08 \\
\hline $\begin{array}{l}\text { 12. Present oSIM: prop. } \\
\text { compatible links }\end{array}$ & $0.81(0.33)$ & & & & & & & & & & & & $.22^{* *}$ & $-.26^{* * *}$ & $.19^{*}$ \\
\hline 13. Present life satisfaction & $3.57(0.92)$ & & & & & & & & & & & & $\alpha=.87$ & $-.47^{* * *}$ & $.19^{*}$ \\
\hline 14. Present depression & $1.80(0.63)$ & & & & & & & & & & & & & $\alpha=.88$ & $-.38^{* * *}$ \\
\hline $\begin{array}{l}\text { 15. Present attachment } \\
\text { to child }\end{array}$ & $4.01(0.57)$ & & & & & & & & & & & & & & $\alpha=.84$ \\
\hline
\end{tabular}


Table A3. Means, standard deviations (in parentheses) and correlations between oSIM variables on past and present maps and outcome variables (Study 4).

\begin{tabular}{|c|c|c|c|c|c|c|c|c|c|c|c|c|c|c|c|}
\hline & $M(S D)$ & 2 & 3 & 4 & 5 & 6 & 7 & 8 & 9 & 10 & 11 & 12 & 13 & 14 & 15 \\
\hline $\begin{array}{l}\text { 1. Past oSIM: Total number of } \\
\text { groups }\end{array}$ & $2.66(1.41)$ & $.91^{* * *}$ & $.85^{* * *}$ & $.57^{* * *}$ & $.32^{* * *}$ & $.30^{* * *}$ & $.66^{* * *}$ & $.62^{* * *}$ & $.59^{* * *}$ & $.32^{* * *}$ & $.29^{* * *}$ & $.23^{* * *}$ & $.18^{*}$ & -.09 & .12 \\
\hline $\begin{array}{l}\text { 2. Past oSIM: Number of } \\
\text { positive groups }\end{array}$ & $2.35(1.55)$ & & $.94^{* * *}$ & $.68^{* * *}$ & $.36^{* * *}$ & $.35^{* * *}$ & $.67^{* * *}$ & $.66^{* * *}$ & $.64^{* * *}$ & $.36^{* * *}$ & $.26^{* * *}$ & $.31^{* * *}$ & $.22^{* *}$ & -.13 & $.17^{*}$ \\
\hline $\begin{array}{l}\text { 3. Past oSIM: Number of } \\
\text { representative groups }\end{array}$ & $2.16(1.51)$ & & & $.73^{* * *}$ & $.35^{* * *}$ & $.33^{* * *}$ & $.62^{* * *}$ & $.62^{* *}$ & $.63^{* * *}$ & $.41^{* * *}$ & $.24^{* * *}$ & $.31^{* * *}$ & $.25^{* *}$ & -.16 & .20 \\
\hline $\begin{array}{l}\text { 4. Past oSIM: Number of } \\
\text { supportive groups }\end{array}$ & $1.55(1.24)$ & & & & $.32^{* * *}$ & $.33^{* * *}$ & $.42^{* * *}$ & $.41^{* * *}$ & $.45^{* * *}$ & $.48^{* * *}$ & $.14^{*}$ & $.27^{* * *}$ & $.21^{* *}$ & -.11 & .14 \\
\hline $\begin{array}{l}\text { 5. Past oSIM: Number of high- } \\
\text { contact groups }\end{array}$ & $0.90(0.96)$ & & & & & $.17^{* * *}$ & $.26^{* * *}$ & $.28^{* * *}$ & $.28^{* * *}$ & .18 & $.39^{* * *}$ & $.15^{* *}$ & .01 & $.03^{*}$ & $<.01$ \\
\hline $\begin{array}{l}\text { 6. Past oSIM: Number of prop. } \\
\text { compatible links }\end{array}$ & $0.47(0.48)$ & & & & & & $.31^{* *}$ & $.31^{* * *}$ & $.31^{* * *}$ & $.28^{* * *}$ & $.22^{*}$ & $.52^{* * *}$ & $.21^{*}$ & -.12 & .12 \\
\hline $\begin{array}{l}\text { 7. Present oSIM: Total number } \\
\text { of groups }\end{array}$ & $3.19(1.64)$ & & & & & & & $.93^{* * *}$ & $.86^{* * *}$ & $.63^{* * *}$ & $.41^{* * *}$ & $.37^{* * *}$ & $.15^{*}$ & -.03 & .01 \\
\hline $\begin{array}{l}\text { 8. Present oSIM: Number of } \\
\text { positive groups }\end{array}$ & $2.64(1.86)$ & & & & & & & & $.92^{* * *}$ & $.67^{* * *}$ & $.39^{* * *}$ & $.38^{* * *}$ & $.19^{* *}$ & -.06 & .04 \\
\hline $\begin{array}{l}\text { 9. Present oSIM: Number of } \\
\text { representative groups }\end{array}$ & $2.41(1.73)$ & & & & & & & & & $.72^{* * *}$ & $.41^{* * *}$ & $.37^{* * *}$ & $.23^{* * *}$ & -.10 & .10 \\
\hline $\begin{array}{l}\text { 10. Present oSIM: Number of } \\
\text { supportive groups }\end{array}$ & $1.65(1.35)$ & & & & & & & & & & $.37^{* * *}$ & $.33^{* * *}$ & $.22^{* *}$ & -.05 & .05 \\
\hline $\begin{array}{l}\text { 11. Present oSIM: Number of } \\
\text { high-contact groups }\end{array}$ & $0.47(0.74)$ & & & & & & & & & & & $.25^{*}$ & -.08 & .15 & -.09 \\
\hline $\begin{array}{l}\text { 12. Present oSIM: Number of } \\
\text { prop. compatible links }\end{array}$ & $0.59(0.47)$ & & & & & & & & & & & & $.15^{* *}$ & .03 & .10 \\
\hline 13. Present life satisfaction & $3.44(0.10)$ & & & & & & & & & & & & $\alpha=.91$ & $-.65^{* * *}$ & $.65^{* * *}$ \\
\hline 14. Present depression & $1.67(0.59)$ & & & & & & & & & & & & & $\alpha=.88$ & $-.48^{* * *}$ \\
\hline $\begin{array}{l}\text { 15. Present adjustment to } \\
\text { retirement }\end{array}$ & $3.49(0.80)$ & & & & & & & & & & & & & & $\alpha=.88$ \\
\hline
\end{tabular}


Click here to access/download

Supplemental Material

oSIM_SupplementaryMaterials_RR_02_SUBMITTED_08

.08.19.docx 